\title{
Trimetallic composite nanofibers for antibacterial and photocatalytic dye degradation of mixed dye water
}

\author{
Ashish Gupta $^{1}$ (D) Nayna Khosla ${ }^{1} \cdot$ V. Govindasamy ${ }^{2} \cdot$ Amit Saini $^{1} \cdot$ K. Annapurna ${ }^{2} \cdot$ S. R. Dhakate ${ }^{1}$ (i)
}

Received: 3 June 2020 / Accepted: 13 August 2020 / Published online: 25 August 2020

(c) King Abdulaziz City for Science and Technology 2020

\begin{abstract}
Membrane technology is an advanced approach to making a healthier and cleaner environment. Using such catalytic membrane technology to get clean, usable water by removal of dye impurities as well as pathogenic microbes is the main goal behind the research work. Here, we present the synthesis and efficacy study of polymethyl methacrylate (PMMA)-based Ag/ $\mathrm{ZnO} / \mathrm{TiO}_{2}$ trimetallic bifunctional nanofibers with antibacterial and photocatalytic activity. The nanofibers have been proven to be effective for the degradation of methylene blue (MB 93.4\%), rhodamine B (Rh 34.6\%), auramine-O (Au 65.0\%) and fuchsin basic (FB 69.8\%) dyes individually within $90 \mathrm{~min}$ in daylight. The study is further extended in abating a mixture of these dyes from contaminated water using composite nanofibers. Also, in the case of a mixture of these dyes ( 3 ppm each), nanofibers show dye degradation efficiency (DDE) of 90.9\% (MB), 62.4\% (Au) and 90.3\% (FB and Rh) in 60 min. The role of $\mathrm{Ag}$ nanoparticles with a synergic photocatalytic effect on $\mathrm{ZnO}$ and $\mathrm{TiO}_{2}$ is also demonstrated. Also, $\mathrm{PMMA} / \mathrm{ZnO} / \mathrm{TiO}_{2}$ composite fiber membrane in synergy with silver particles shows better antibacterial activity against Gram-negative bacteria E. coli, making $\mathrm{PMMA} / \mathrm{Ag} / \mathrm{ZnO} / \mathrm{TiO}_{2}$ fibers a promising candidate in water purification.
\end{abstract}

Keywords Nanofibers $\cdot$ Membrane $\cdot$ Photocatalysis $\cdot$ Antibacterial $\cdot$ Dye mixture

\section{Introduction}

With an increase in industrialization, population and climate change, water pollution has been increasing day by day. According to a survey (Malwal and Gopinath 2017; Thavasi et al. 2008), freshwater shortage and crisis may increase to $50 \%$ by 2025 and $75 \%$ by 2075 globally. Different pollutants such as dyes, fluoride and heavy metal ions contaminate freshwater, and are hazardous to human beings (Sharma et al. 2014). The polluted water bodies often act as a host breeding ground for bacteria (such as E. coli) and pathogens. Statistical data show that about $20 \%$ of water pollution is due

Electronic supplementary material The online version of this article (https://doi.org/10.1007/s13204-020-01540-6) contains supplementary material, which is available to authorized users.

S. R. Dhakate

dhakate@nplindia.org

1 Advanced Carbon Products and Metrology, CSIRNational Physical Laboratory, Dr. K.S. Krishnan Marg, New Delhi 110012, India

2 Division of Microbiology, Indian Agricultural Research Institute, Pusa Campus, New Delhi 110012, India to various dyes released in the flowing water (Chavan 2001). Owing to the need of the hour, different water treatment and purification methods such as ozonation (Piaskowski et al. 2018), flocculation(Guo et al. 2018), floatation, and electrolysis (Mokif 2019) have been often utilized for dye removal (Galindo et al. 2001). However, due to the high stability of the dyes and aromatic nature of the dye molecules, biological treatment methods are ineffective for degradation (Arslan and Balcioğlu 1999; Correia et al. 1994; Moore et al. 1989; Patil and Shinde 1988). The other traditional physical removal techniques such as adsorption on activated carbon (Aboua et al. 2015), ultrafiltration(Bouazizi et al. 2017; Hidalgo et al. 2018), reverse osmosis(Sahinkaya et al. 2018), and coagulation by chemical agents(Butler et al. 2017) only transfer the organic compounds from water to another phase, thus causing secondary pollution resulting in enhanced posttreatment cost of solid waste management (Cooper 1993; Galindo et al. 2001). Several metal oxide semiconductor materials are now being used for their excellent photocatalytic activity such as $\mathrm{ZnO}, \mathrm{TiO}_{2}$, and $\mathrm{CeO}_{2}$ (Younis et al. 2018), and metal sulfides (Shamraiz et al. 2016) such as MnS (Hussain et al. 2019a) and CoS (Hussain et al. 2019b) in abating harmful dyes from drinking water. 
These photocatalytic agents can overcome the problem of secondary waste; however, these are difficult to remove from water post-purification due to being in powder form.

To overcome the difficulty of removal of photocatalytic agents post-water treatment, photocatalytic membrane reactors have been developed using various membrane techniques (Molinari et al. 2000, 2001, 2002a, b; Sopajaree et al. 1999a, b), but these processes are of high cost. On the other hand, electrospinning is a simple technique that yields nanofibers with excellent physicochemical properties(Gupta et al. 2019; Moheman et al. 2016; Sharma et al. 2014), which are beneficial for the photocatalytic reaction due to higher mesoporosity and specific surface area. This enhances solar light absorption with visible light sensitivity, longer lifetimes of photogenerated charge carriers and long nanofibrous structure for efficient charge transfer and recovery. Enhancement of photocatalytic activity has been an active area of research since a very long time and it is reported that composite semiconductor materials have higher photocatalytic activity than a single metal oxide semiconductor (Pei and Leung 2013; Sehar et al. 2019). Therefore, bi-complex nanofibers produced by electrospinning have proven to be a promising water treatment material (Yar et al. 2017). Transition metal oxides such as $\mathrm{ZnO}$ and $\mathrm{TiO}_{2}$ are used as active photocatalysts due to their electronic structure with a bandgap energy $\sim 3 \mathrm{eV}$ and, thus, can easily generate charge carriers when stimulated with the light of energy lying in the near-visible region. Hence, their performance has been observed even in suitable sunlight (Gupta et al. 2015a). The development of combined photocatalysts and use of solar radiations (cheap, renewable source $\lambda>300 \mathrm{~nm}$ ) are sensible for the reduction of water pollution caused by dye compounds because of the mild conditions required and their efficiency in mineralization (Augugliaro et al. 2002; Sakthivel et al. 2003; Stylidi et al. 2003; Zhang 1996). These catalysts are non-toxic, inexpensive and possess relatively high chemical stability (Pirkanniemi and Sillanpää 2002). However, these oxide materials suffer from a high recombination rate of photogenerated carriers. Recent studies have shown that combining oxides with metal particles such as silver (Ag) (Bian et al. 2020), gadolinium (Gd) (Younis et al. 2016), or indium (In) (Younis et al. 2018) can lower the recombination rate and enhance the photocatalytic activity. Silver $(\mathrm{Ag})$ is also well known to possess antibacterial properties (Nigussie et al. 2018) and it can act as a suitable scavenger during photocatalysis, thereby preventing further recombination and enhancing the photocatalytic efficiency (Fageria et al. 2014). In literature single or bi-metal oxide polymer composite nanofibers are reported for photocatalytic and antibacterial action. It is reported that $\mathrm{TiO}_{2}-\mathrm{ZnO}$ nanocomposites can have better and enhanced photocatalytic and antibacterial performance as compared to individual (Di Mauro et al. 2017; Im et al. 2008; Pant et al. 2013; Yar et al. 2017; Zhao et al. 2017).
Polymers are low-cost materials and immobilization of photocatalytic agents over or inside polymer nanofibers is an effective low-cost method. Polymethyl methacrylate (PMMA) is a lightweight, low density, optically transparent and water-insoluble polymer (Kumar et al. 2020) and it is used for immobilization of catalysts as well (Kumar et al. 2013). Also, being hydrophobic, PMMA interacts with aromatic dye molecules and increases dye removal capacity from water (Di Mauro et al. 2017). Also, the immobilization of active particles in the polymer matrix eliminates the difficulty in the separation of materials after dye degradation.

The key importance of the present investigation is to evaluate the dual application of electrospun nanofiber membrane for removal of dyes (a mixture of dyes) from contaminated water and antibacterial activity. Numerous studies are available on the removal of individual dyes (Phan and Kim 2020; Zhao et al. 2017); as one application, however, recently Hussain et al., demonstrated metal sulfides-based materials for purification of water as well as anode material for batteries (Hussain et al. 2019a, b). To our best knowledge, there is no study available in the literature on the removal of dye mixture and antibacterial activities by using nanofibers.

Therefore in the present investigation, the hybrid electrospun polymer nanofiber membrane has been developed for dual applications. The PMMA-based electrospun nanofibers encapsulated by tri-metal nanoparticles $\left(\mathrm{Ag} / \mathrm{ZnO} / \mathrm{TiO}_{2}\right)$ have been synthesized and these trimetallic nanofiber membranes are characterized by different techniques and studied for both dye degradation and antibacterial activity in the presence of sunlight. The dyes utilized in the present research work are methylene blue (MB), rhodamine $\mathrm{B}(\mathrm{Rh})$, auramine- $O(\mathrm{Au})$ and fuchsin basic (FB). The efficiency study of nanofibers in abating these dyes individually as well as their mixture solution in the same and different concentrations is carried out.

\section{Experimental}

\section{Materials}

PMMA (MW 120,000 by GPC), $\mathrm{TiO}_{2}$ (99\% assay) and silver nitrate $\left(\mathrm{AgNO}_{3}\right)$ from Rankem and Sigma-Aldrich, respectively; zinc acetate (assay: 99.5\%) from $\mathrm{CDH}$, New Delhi; $N, N$ dimethyl formamide (DMF) of assay $99.0 \%$ from Thomas Baker; ethanol from Changshu Hong sheng Fine Chemical Co Ltd. were procured and used without further purification. Nutrient agar powder was procured from HiMedia, India.

\section{Synthesis of $\mathrm{ZnO}$ nanoparticles}

$\mathrm{ZnO}$ nanoparticles were synthesized by a simple sol-gel method as described elsewhere (Vanaja et al. 2016). The 
$0.2 \mathrm{M}$ zinc acetate solution was prepared in $50 \mathrm{ml}$ of deionized (DI) water by stirring at $80{ }^{\circ} \mathrm{C}$ and marked as solution I. The $3 \mathrm{M} \mathrm{NaOH}$ solution was also prepared separately in $50 \mathrm{ml}$ DI water termed as solution II. Solution II was added dropwise to the solution I with constant stirring. Once both the solutions were mixed well, a gel formation was observed. Afterward, the obtained gel was kept for aging for 4-5 $\mathrm{h}$ and then filtered out. The residual gel obtained on filter paper was washed with DI water until the filtrate attained a $\mathrm{pH}$ of 7. Finally, the residue was dried in an oven at $80{ }^{\circ} \mathrm{C}$ for $6 \mathrm{~h}$ and later heat treated at temperature $700^{\circ} \mathrm{C}$ in a quartz furnace at a ramp rate of $5{ }^{\circ} \mathrm{C} / \mathrm{min}$ for $3 \mathrm{~h}$ to get $\mathrm{ZnO}$ nanoparticles.

\section{Synthesis of $\mathrm{TiO}_{2}$ nanoparticles}

As purchased, $\mathrm{TiO}_{2}$ particles were heat treated at temperature $700{ }^{\circ} \mathrm{C}$ for $3 \mathrm{~h}$ in a quartz furnace in air atmosphere to remove any volatiles and moisture.

\section{Synthesis of silver nanoparticles}

Silver nanoparticles were synthesized by the in situ solvent reduction process (Pastoriza-Santos and Liz-Marzán 2009) with some modification. In brief, $7 \mathrm{mM}$ silver nitrate along with $20 \mathrm{mM}$ of polyvinylpyrrolidone (PVP) solution was added to $100 \mathrm{ml}$ of DMF and the solution was kept on a magnetic stirrer (IKA C-MAG HS7) at room temperature for $24 \mathrm{~h}$ with $2 \mathrm{~h} \mathrm{UV}$ light exposure. Gradually, the solution turned yellow color after aging. The color change of the solution into yellow signifies the formation of silver nanoparticles (Chaudhary et al. 2014).

\section{Synthesis of PMMA/ZnO/TiO ${ }_{2}$ and PMMA/Ag/ZnO/TiO nanofibers}

For the synthesis of PMMA/ZnO/TiO ${ }_{2}$ nanofibers, $20 \% \mathrm{w} / \mathrm{w}$ of $\mathrm{ZnO}$ and $\mathrm{TiO}_{2}$ particles (1:1) w.r.t. polymer were added in $8.2 \mathrm{~g}$ of DMF and kept in an ultrasonication bath for $2 \mathrm{~h}$ for dispersion. The $1.8 \mathrm{~g}$ of PMMA polymer was then added to the solution and it was kept for magnetic stirring for $6 \mathrm{~h}$ for uniform dispersion. Similarly, for preparing PMMA/Ag/ $\mathrm{ZnO} / \mathrm{TiO}_{2}$ fibers, $20 \% \mathrm{w} / \mathrm{w}$ of $\mathrm{ZnO}$ and $\mathrm{TiO}_{2}$ particles (1:1) were dispersed in DMF solvent containing Ag nanoparticles using ultrasonication. Afterward, the PMMA polymer was added $1.8 \mathrm{~g}$ as in the above case of PMMA $\mathrm{Ag} / \mathrm{ZnO} / \mathrm{TiO}_{2}$ and stirred well to make uniform dispersion. The above prepared solution of PMMA/ZnO/TiO ${ }_{2}$ and PMMA Ag/ZnO/ $\mathrm{TiO}_{2}$ was filled in the $5 \mathrm{ml}$ syringe with a metallic needle ( $24 \mathrm{G}, 0.5 \mathrm{~mm}$ dia) separately and subjected to the electrospinning method at the optimized instrumental parameters, i.e., flow rate $0.4 \mathrm{ml} / \mathrm{h}$, voltage $12 \mathrm{kV}$, and tip to collector distance $25 \mathrm{~cm}$. PMMA/ZnO/ $\mathrm{TiO}_{2}$ and $\mathrm{PMMA} / \mathrm{Ag} / \mathrm{ZnO} /$ $\mathrm{TiO}_{2}$ nanofibers have been designated as PZT and PAZT, respectively, throughout the manuscript. Figure 1 shows the schematics for the synthesis of PAZT nanofibers.

\section{Characterization techniques}

The as-synthesized nanoparticles and fibres were characterized for their surface morphology using scanning electron microscope (SEM, VPSEM Zeiss EVO MA-10, Germany equipped with lanthanum hexaboride electron gun) and transmission electron microscope (TEM, Technai G-20 S-TWIN) instruments. Elemental analysis was carried out using EDAX (Oxford Instruments Aztec Energy EDX system with $80 \mathrm{~mm}$ X-Max silicon drift detector). Raman study was performed using Renishaw in-Via microRaman spectrometer with an excitation source of $514.5 \mathrm{~nm}$ $(E=2.41 \mathrm{eV})$. The structural information of composite nanofibers was extracted by X-ray diffraction (XRD, Rigaku diffractometer $\mathrm{Cu}-\mathrm{K} \alpha$ radiation) analysis. Dye degradation studies were carried out using a UV spectrophotometer (Specord 210 Plus double beam).

\section{Dye solution preparation}

To study the photocatalytic removal of dyes using PZT and PAZT nanofibers, methylene blue (MB) dye is taken as a model dye primarily. The concentration of MB dye was prepared at $100 \mathrm{ppm}$ as a standard solution and further diluted to prepare 1, 3, and $5 \mathrm{ppm}$. The PZT and PAZT

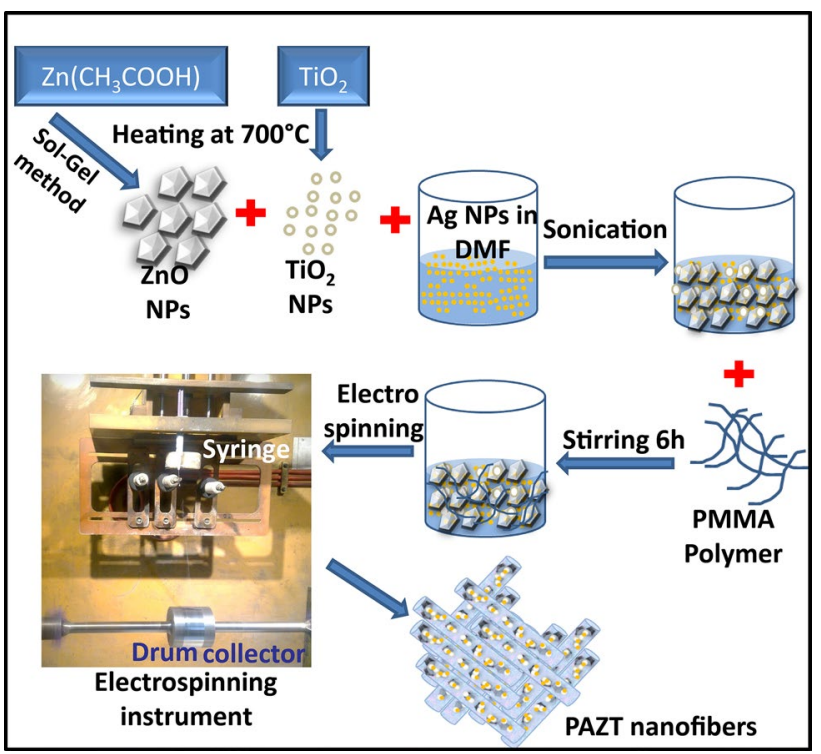

Fig. 1 Schematic of the synthesis process for PAZT nanofibers

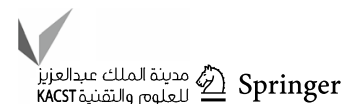


nanofibers were tested with $3 \mathrm{ppm}$ concentration of MB dye. $2 \mathrm{mg}$ of the electrospun nanofibers was weighed on a microbalance and added into $10 \mathrm{~mL}$ of aqueous dye solution with varying concentration. Then the photocatalytic decolorization of dyes was investigated under the sunlight in the presence/absence of fabricated nanofibers catalysts under irradiation for a given time. The remaining concentration of the dye was evaluated by using the UV-vis spectroscopy from the decrease in corresponding absorbance value as compared to a standard one. The dye degradation efficiency (DDE) is calculated by using the following equation:

$\operatorname{DDE}(\%)=\frac{A_{\mathrm{o}}-A}{A_{\mathrm{o}}} \times 100$

where $A \mathrm{o}$ is the absorbance for the initial concentration of the dye before irradiation and $A$ is the absorbance for the concentration of the dye after a certain irradiation time.

Further after observing the better efficacy of PAZT over PZT, the PAZT nanofibers were also tested for DDE against $\mathrm{MB}$ dye, fuchsin basic $(\mathrm{Fb})$, auramine- $O(\mathrm{Au})$ and rhodamine $\mathrm{B}(\mathrm{Rh})$ individually. For individual testing, the dye concentration was prepared as $3 \mathrm{ppm}$ for MB, $5 \mathrm{ppm}$ for $\mathrm{Au}, 1 \mathrm{ppm}$ for each FB and Rh. To study the effect of concentration and time on the photocatalytic action of the PAZT nanofibers were the prime goals. A different set of experiments were carried out on individual dyes as well as a mixture of these dyes.

A mixed dye composed of all four dyes was used in the present work, i.e., MB, Au, FB and Rh. These were mixed in the concentration of $3 \mathrm{ppm}$ each as well as in different concentrations (MB (3 ppm) Au (2 ppm) FB and Rh $(1 \mathrm{ppm}))$ in separate experiments. Self-degradation of dyes was also considered as control under identical conditions for each dye individually as well as in the mixed state.

\section{Zone of inhibition test}

Nutrient agar is commonly used to culture various microorganisms in the laboratory to carry out the experiments. The nutrient agar solution was prepared and autoclaved for sterilization and poured into disposable Petri plates under laminar airflow to exclude the microbial contamination which might come during the experiment. $1 \mathrm{ml}$ of Gramnegative Escherichia coli (E. coli grew on LB broth overnight) strain $D \# 5 \alpha$ culture was taken and diluted to $10^{-1}$. This microbial solution was spread over the solidified agar plates and small pieces of nanofibers were placed over the agar plates. The plates were incubated for $20 \mathrm{~h}$ at $37{ }^{\circ} \mathrm{C}$. After $20 \mathrm{~h}$ incubation, the antibacterial effect of the PZT and PAZT fibers on E. coli strain D\#5 $\alpha$ was observed as a zone of inhibition around the fibers. The zone of inhibition was calculated from the area surrounding the nanofiber pieces using Image $\mathbf{J}$ software analysis.

\section{Results and discussion}

\section{SEM analysis}

The morphology of the synthesized nanoparticles and nanofibers were observed by SEM. Figure 2 shows the SEM images of $\mathrm{ZnO}$ nanoparticles, $\mathrm{TiO}_{2}$ nanoparticles, PZT fibers and PAZT fibers. In Fig. 2a the $\mathrm{ZnO}$ nanoparticles are observed with size less than $200 \mathrm{~nm}$ measured using Image $\mathrm{J}$ software and confirmed from TEM analysis. Most of the $\mathrm{ZnO}$ particles have a hexagonal shape, as clearly seen in the magnified image shown in the inset of Fig. 2a. The $\mathrm{TiO}_{2}$ particles, heat treated at $700{ }^{\circ} \mathrm{C}$ and sonicated for $120 \mathrm{~min}$, were observed to be of almost spherical shape (Fig. 2b) and diameter in the range 80-140 nm measured using Image J.

Figure 2c shows the SEM image of PZT fibers having semi-aligned network structure with a diameter in the range 1.1-1.5 $\mu \mathrm{m}$. The fiber diameter is comparatively more, which may be due to low stretching during electrospinning and deposition of nanoparticles on the surface of fibers. On the other hand, in the case of PAZT nanofibers, the fiber diameter decreases to $0.7-1.2 \mu \mathrm{m}$ at the same electrospinning processing parameters, due to the presence of Ag nanoparticles in the solution that increases the overall conductivity of the solution (Phan et al. 2020), resulting in more stretching of fibers during electrospinning of solution which attributes to a decrease in the fiber diameter (Fig. 2d). The deposition of particles on the surface of fibers can promote the activity of composite fibers in UV radiation. EDS mapping analysis of PAZT nanofibers shows the presence of $\mathrm{Zn}, \mathrm{O}, \mathrm{Ti}, \mathrm{C}$, and $\mathrm{Ag}$ elements in the fibers (supplementary fig. S1).

\section{TEM analysis}

Figure 3 shows TEM images for $\mathrm{ZnO}$ particles, PZT fibers and PAZT fibers. ZnO particles were sonicated first before preparing a sample for TEM which helps in separating aggregates. Figure $3 \mathrm{a}$ shows that $\mathrm{ZnO}$ particles are of random size, i.e., $30 \mathrm{~nm}-200 \mathrm{~nm}$. Figure $3 \mathrm{~b}$ shows the HRTEM image of the $\mathrm{ZnO}$ particle, which shows the parallel fringes. These fringes were further magnified using FFT in Gatan software (inset Fig. 3b) measuring a $d$-spacing of $0.25 \mathrm{~nm}$ (taken from an average of 10 fringes) prominently for the hkl plane (101), which is also confirmed from XRD analysis. Figure $3 \mathrm{c}$ shows the TEM image of PZT fibers. The nanoparticles of size $60-170 \mathrm{~nm}$ (measured using image $\mathrm{J}$ ) can be seen clearly on the surface of fibers. The polymer fibers get swelled due to solvent absorption during the sonication 


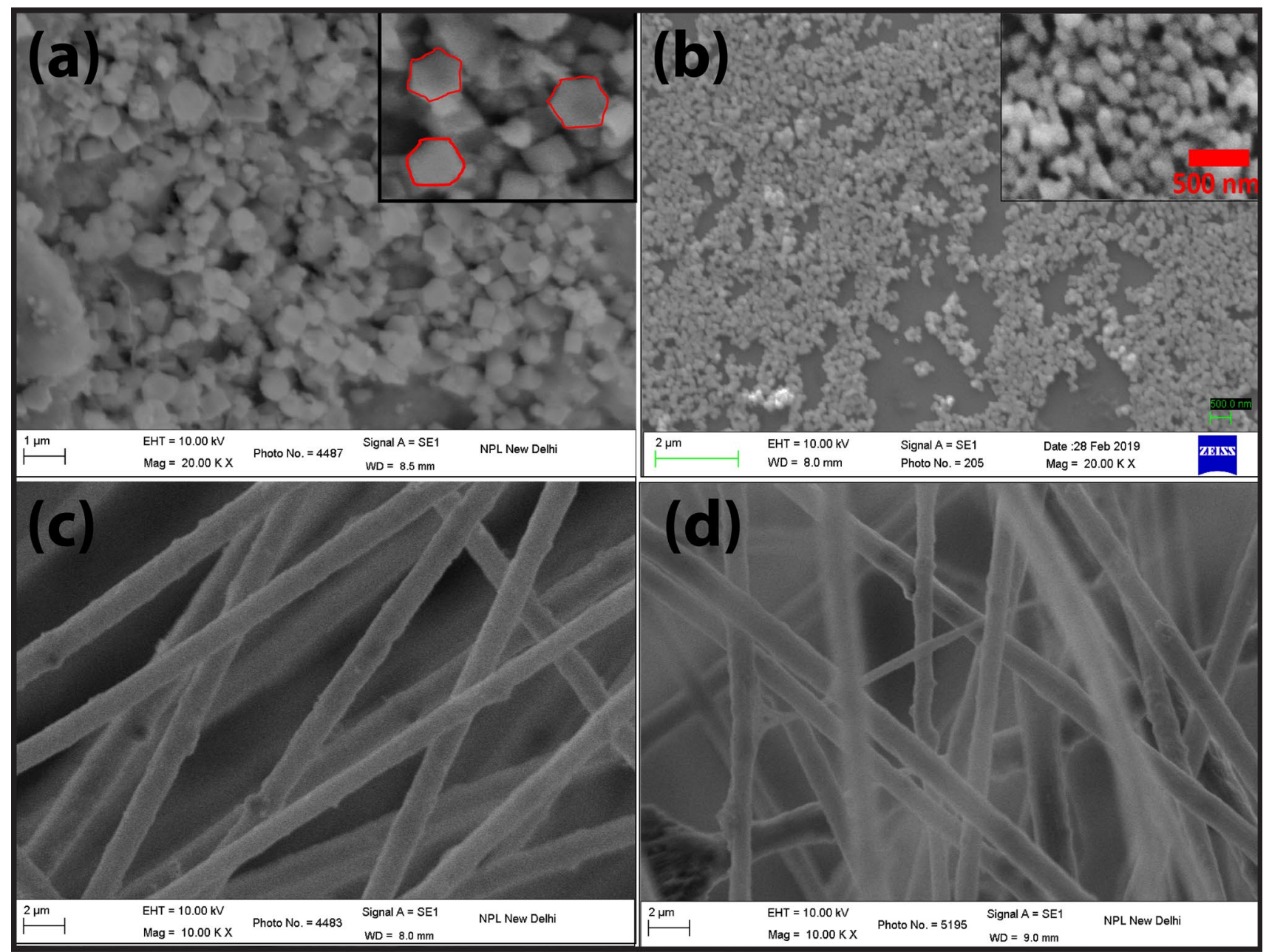

Fig. 2 SEM images of as-synthesized a $\mathrm{ZnO}$ particles, $\mathbf{b} \mathrm{TiO}_{2}$ particles, $\mathbf{c}$ PZT fibers, $\mathbf{d}$ PAZT fibers

process and adapted for sample preparation. Similarly, nanoparticles can be seen on the PAZT fibers (Fig. 3d). These nanoparticles may be present inside the fibers or on the surface. However, in a more clear view (inset Fig. $3\left(\mathrm{~d}_{1}\right)$, from contrast change, it seems that these particles have a coating on their surface. It can be assumed that due to polymer coating (size 9-10 nm), a clear planar structure of the particles was not observed.

\section{XRD analysis PZT and PAZT}

Figure 4 shows the XRD spectra for $\mathrm{ZnO}, \mathrm{TiO}_{2}, \mathrm{PZT}$ nanofibers and PAZT nanofibers. Figure $4 \mathrm{a}$ shows $\mathrm{ZnO}$ is present in hexagonal wurtzite polycrystalline structure form and matches well with JCPDS file 36-1451. It shows the presence of peaks at $2 \theta$ values $31.86^{\circ}, 34.49^{\circ}, 36.36^{\circ}, 47.6^{\circ}$, $56.64^{\circ}$, and $69.00^{\circ}$, for hkl value (100), (002), (101), (102), (103) and (112), respectively. Similarly, Fig. 3b shows the XRD curve for $\mathrm{TiO}_{2}$ particles which matches well with the JCPDS file 21-1272 showing $\mathrm{TiO}_{2}$ is present in anatase polycrystalline structure form. More prominent peaks are observed at $2 \theta$ values $25.5^{\circ}, 37.86^{\circ}, 48.22^{\circ}, 54.00^{\circ}, 55.26^{\circ}$ and $66.70^{\circ}$ for hkl values (101), (004), (200), (105), (211) and (204), respectively. The PMMA nanofibers containing $\mathrm{ZnO}$ and $\mathrm{TiO}_{2}$ (Fig. 3c) were also characterized using $\mathrm{XRD}$ and reveal the prominent peaks of $\mathrm{TiO}_{2}$ for hkl planes (101) and (004) with weak peaks representing $\mathrm{ZnO}$ for hkl planes (100) and (002). It can be concluded that $\mathrm{TiO}_{2}$ may be present on the surface of nanofibers showing higher peak intensity as compared to $\mathrm{ZnO}$, which may be encapsulated inside the fibers. Similar to the above case, in the case of PAZT fibers, the same XRD peaks for $\mathrm{ZnO}$ and $\mathrm{TiO}_{2}$ were observed while peaks for silver are completely hindered due to the high intensity of XRD peaks for substrate aluminum. Aluminum shows XRD peaks at $2 \theta$ values $38.45^{\circ}, 44.71^{\circ}$, $65.09^{\circ}$, and $78.23^{\circ}$ for the hkl planes (111), (200), (220) and (311), corresponding to JCPDS no. 89-4037, while Ag also shows peaks nearly at the same positions. This is the reason that the peak for $\mathrm{Ag}$ cannot be identified clearly. The XRD peaks at $2 \theta$ values $65^{\circ}$ and $78^{\circ}$ are shown separately 

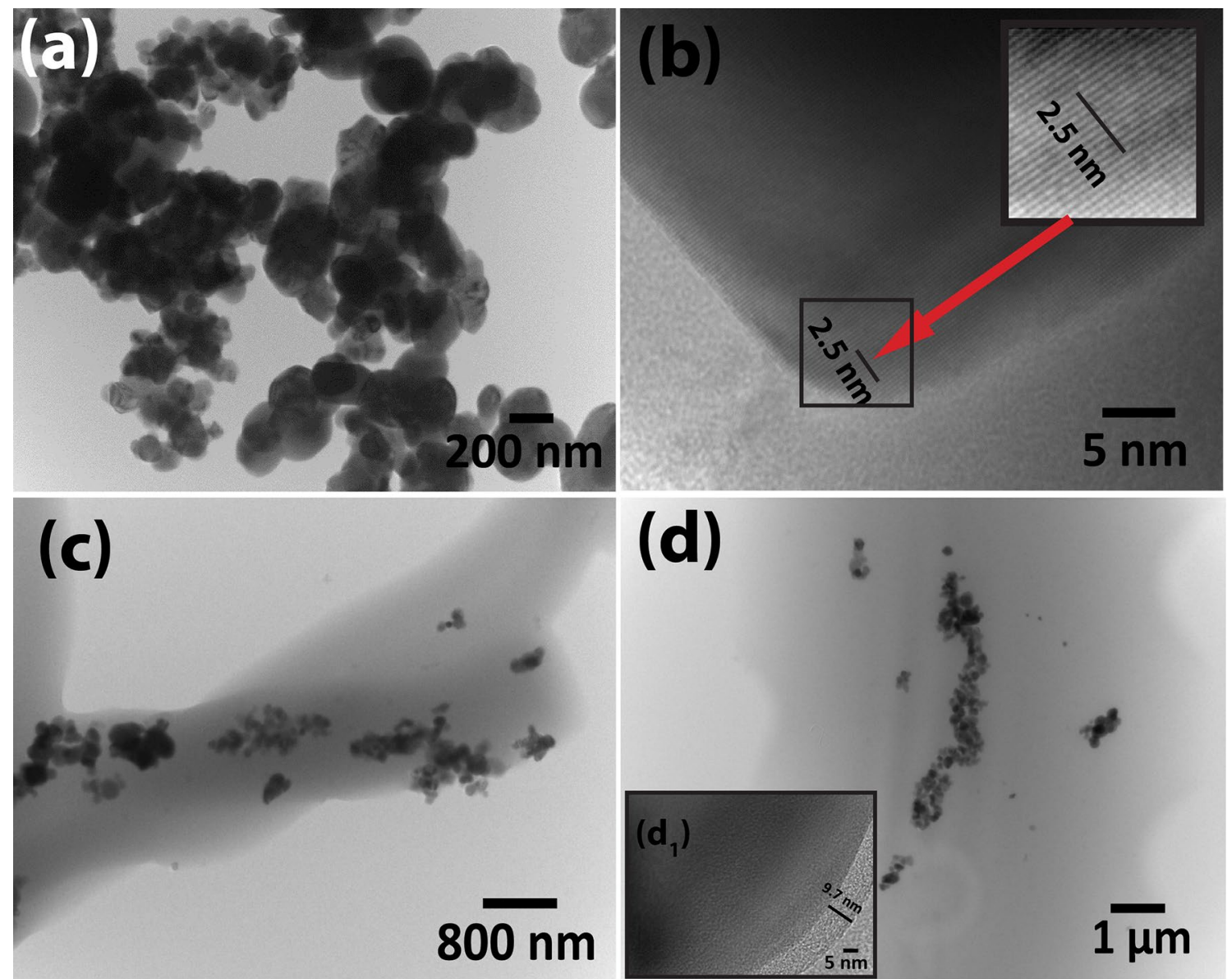

Fig. 3 TEM images of a ZnO particles, $\mathbf{b}$ HRTEM of ZnO particles, $\mathbf{c}$ PZT fibers and $\mathbf{d}$ PAZT fibers containing particles

as a magnified image in the inset of Fig. $4 c$, d. In case of PZT, individual peaks observed at $65.08^{\circ}$ and $78.2^{\circ}$ (inset of Fig. 4c) can be attributed to aluminum the substrate, while in case of PAZT, duplet peaks are observed (inset of Fig. 4d), i.e., at $65.08^{\circ} \& 65.26^{\circ}$ for $(220)$ and $78.2^{\circ}$ and $78.44^{\circ}$ for (311), representing aluminum and silver (JCPDS 03-0921), respectively.

\section{Raman analysis}

Figure 5 shows the Raman spectra for $\mathrm{ZnO}$ particles, $\mathrm{TiO}_{2}$ particles, PZT fibers and PAZT composite fibers. Figure 5a shows the Raman spectrum for as-synthesized $\mathrm{ZnO}$ particles. There are eight sets of zone center optical phonons, according to Group theory, out of which two for the transverse optical (TO) phonons, two for longitudinal optical (LO) phonon, two low and high phonon mode as $E_{2}$ are Raman active. The peak positioned at $99 \mathrm{~cm}^{-1}\left(E_{2}\right.$ low $)$ is dominated by the vibrations of the heavy $\mathrm{Zn}$ sub-lattice. The two phonon modes near 438 and $582.85 \mathrm{~cm}^{-1}$ could be assigned to $E_{2}$ (high) and $\mathrm{A}_{1}(\mathrm{LO})$, respectively. The peak near $438 \mathrm{~cm}^{-1}$ appears due to the presence of oxygen vibrations (Šćepanović et al. 2010) and confirms the wurtzite phase particularly. The phonon mode at $332 \mathrm{~cm}^{-1}$ is a second-order phonon, which generally originates from the zone-boundary phonons of 2E2 (low). The Raman spectrum (Fig. 5b) of $\mathrm{TiO}_{2}$ nanoparticles reveals that four modes, i.e., $\mathrm{A} 1 \mathrm{~g}, 2 \mathrm{~B} 1 \mathrm{~g}$, and $3 \mathrm{Eg}$ are Raman active, positioned at peak values $142.5 \mathrm{~cm}^{-1}(\mathrm{Eg}), 196.6 \mathrm{~cm}^{-1}(\mathrm{Eg}), 395.5 \mathrm{~cm}^{-1}(\mathrm{~B} 1 \mathrm{~g})$, $514.8 \mathrm{~cm}-1(\mathrm{~A} 1 \mathrm{~g}+\mathrm{B} 1 \mathrm{~g})$ and $637.5 \mathrm{~cm}^{-1}(\mathrm{Eg})$. This confirms that $\mathrm{TiO}_{2}$ is present in the anatase phase, determined by group analysis D4h (I41/amd) (Ma et al. 1998).

In the case of PZT nanofibers, the Raman graph (Fig. 5c) shows the characteristic peak of $\mathrm{TiO}_{2}$ at $143(\mathrm{Eg}), 395(\mathrm{~B} 1 \mathrm{~g})$, 519(A1g + B1g) and $639 \mathrm{~cm}^{-1}(\mathrm{Eg})$ (Zhang et al. 2000). A peak appearing near $2951 \mathrm{~cm}^{-1}$ is characteristic of the PMMA polymer (Xia et al. 2012). However, no separate peak related to $\mathrm{ZnO}$ was observed. It may be because $\mathrm{ZnO}$ particles are coated by polymer and small $\mathrm{TiO}_{2}$ particles, making its Raman signal weak enough to observe. Similar to the above case, in the case of PAZT fibers (Fig. 5d), the Raman graph shows the characteristic peak of $\mathrm{TiO}_{2}$ at 143 (Eg), 395.5 (B1g), 519.1 (A1g + B1g), and 639.3 (Eg) $\mathrm{cm}^{-1}$ revealing the presence of anatase $\mathrm{TiO}_{2}$ particles on 

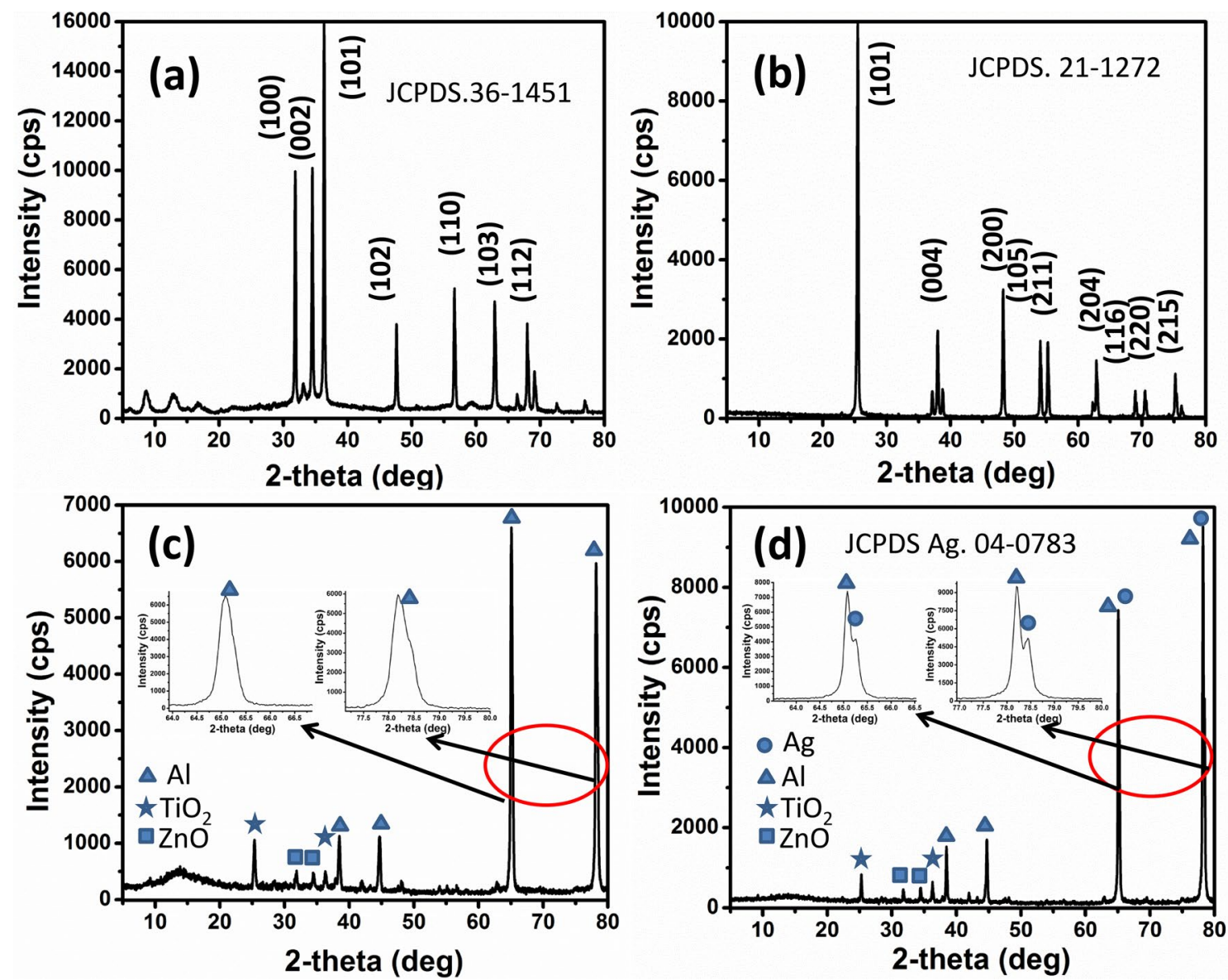

Fig. 4 XRD graph for $\mathbf{a} \mathrm{ZnO}$ particles, $\mathbf{b} \mathrm{TiO}_{2}$ particles, $\mathbf{c}$ PZT and $\mathbf{d}$ PAZT nanofibers

nanofibers. Pure Ag metal particles are Raman inactive (Ag-Ag bonds), so, no separate peak was observed for $\mathrm{Ag}$ particles in Raman analysis (Michaels et al. 1999), revealing no chemical bonding involving $\mathrm{Ag}$ and metal oxides (Zamiri et al. 2014).

\section{PL analysis}

Figure 6 shows the PL spectra of PZT and PAZT composite fibers when excited at $360 \mathrm{~nm}$. The PL graph of PZT fibers shows two regions of emission, highest at region $380-450 \mathrm{~nm}$ (UV) centered at $404 \mathrm{~nm}$ and two weak emissions in the region $482-572 \mathrm{~nm}$ (visible) centered at 500 and $560 \mathrm{~nm}$. The peak in the UV region is due to the recombination of electrons from the conduction band with holes in the valence band; such emission is responsible for dye removal activity of these materials. The weak peaks in the visible regions are due to emission from defect sites in composite fibers as well as photocatalytic agents. Although in the case of PAZT a peak with lower intensity (compare to PZT) is observed in the UV region centered at $404 \mathrm{~nm}$, at the same wavelength as PZT; however, lower intensity results are attributed to low recombination rate (Younis et al. 2016). The recombination rate lowering in PAZT may be due to the presence of silver particles. The decrease in the intensity of emission for PAZT nanofiber with no change in peak position accounts for the interaction between excitons of $\mathrm{ZnO} /$ $\mathrm{TiO}_{2}$ and surface plasmon of Ag nanoparticles (Zheng et al. 2007). Also, in the case of PAZT composite fibers, the peak is not observed in the visible region; this shows the suppression or removal of defect sites that are present in PZT fibers. It may be due to Ag particles that may be trapped in $\mathrm{ZnO}$ defect sites and electron transfer takes place between the energy levels of $\mathrm{ZnO}$ and $\mathrm{Ag}$ metal nanoparticles (Shahi et al. 2020).

\section{UV analysis}

The photocatalytic activity of both PZT and PAZT fibers under solar radiation exposure is studied against MB dye using a UV spectrophotometer. Initially, a standard solution of different concentrations of MB was prepared. Figure 7a shows the UV absorption peaks for a standard solution of $5 \mathrm{ppm}, 3 \mathrm{ppm}$ and $1 \mathrm{ppm}$ with absorbance value of 

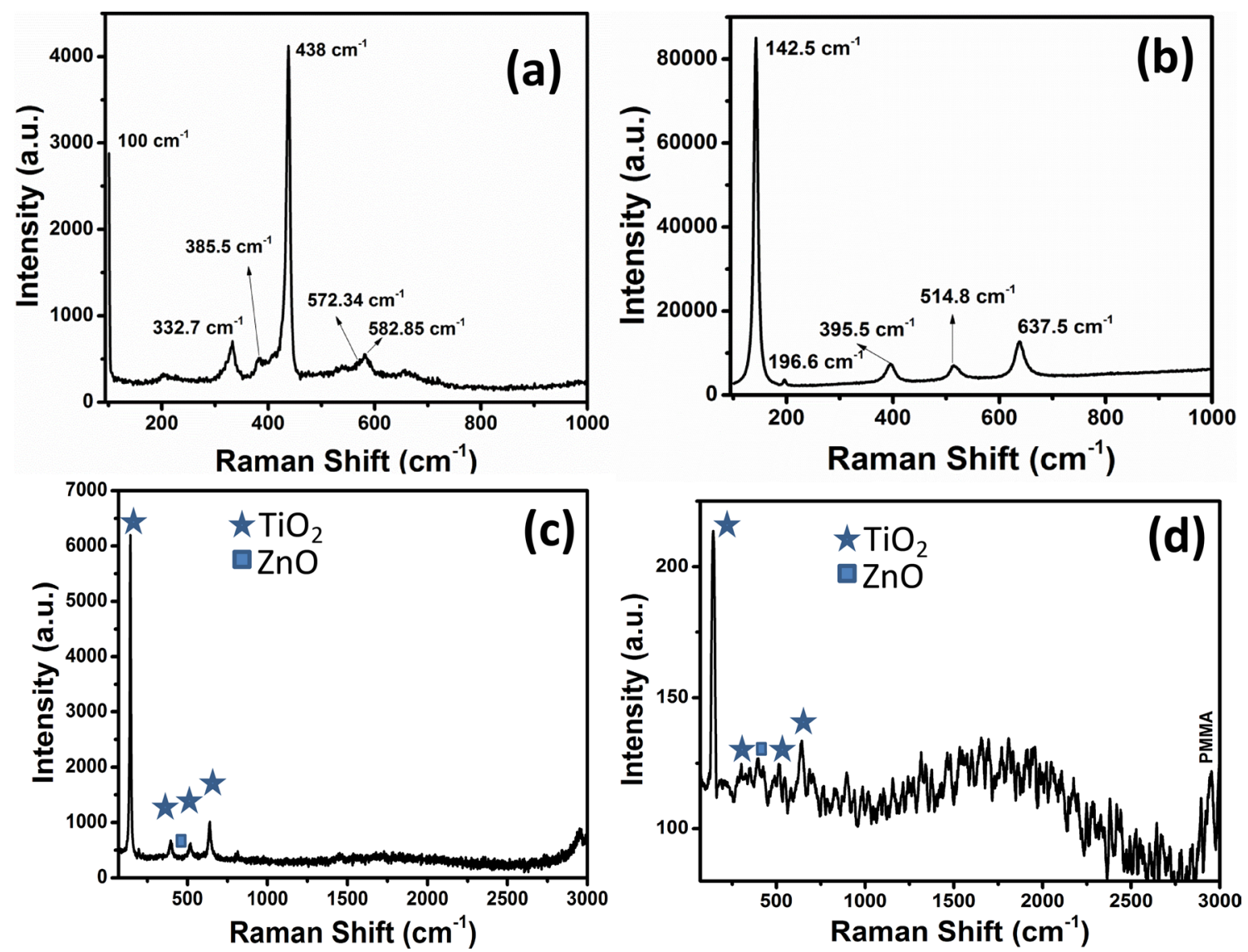

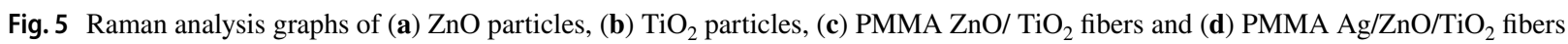

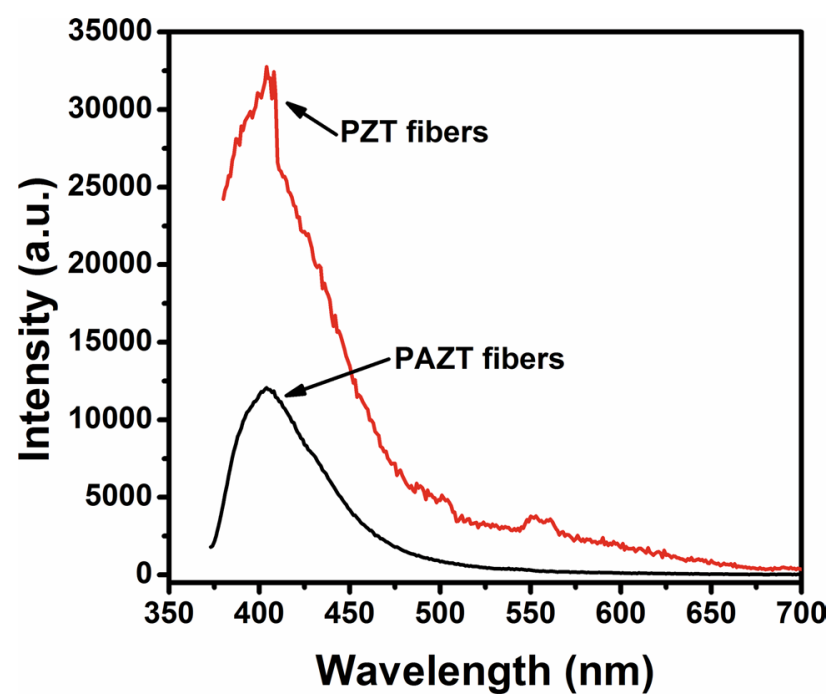

Fig. 6 PL spectrum for PZT and PAZT nanofibers

nearly $0.84,0.50$ and 0.13 , respectively. MB dye solution of concentration $3 \mathrm{ppm}$ is used for further photocatalytic studies in solar radiation. Figure $7 \mathrm{~b}$ shows the change in absorbance for exposing MB solution containing PZT and PAZT fibers for 20 and $40 \mathrm{~min}$. In the case of PZT fibers, the DDE is $25.7 \%$ and $54.2 \%$ for 20 and 40 min respectively, while in the case of PAZT fibers, the DDE against MB dye improves and is 42.7 and $71.2 \%$ in 20 and 40 min, respectively. The main reason for the improved efficacy is the involvement of $\mathrm{Ag}$, which demonstrated the synergistic effect with $\mathrm{ZnO}$ and $\mathrm{TiO}_{2}$ by surface plasmon resonance (SPR) effect, causing lowering of the recombination rate during exposure to solar radiation (Pant et al. 2013) as observed in PL analysis. In the case of the control (green color curve) sample, the degradation of MB dye in $40 \mathrm{~min}$ is observed as only $2.3 \%$.

After observing the better efficacy of PAZT nanofibers in abating MB dye as compared to PZT fibers, the PAZT nanofibers were tested for $\mathrm{MB}, \mathrm{FB}, \mathrm{Au}$ and $\mathrm{Rh}$ for different times. Figure $8 \mathrm{a}$ shows the photocatalytic activity of MB dye at different time intervals of 30,60 and $90 \mathrm{~min}$. The DDE for $3 \mathrm{ppm}$ concentration of MB dye is found to be $51.4 \%, 82.2 \%$, and $93.4 \%$ in 30,60 and $90 \mathrm{~min}$, respectively. The MB dye control exposed to sunlight for $90 \mathrm{~min}$ (Fig. 8a) shows dye degradation of 9\%. Similarly, for Au dye (5 ppm) (Fig. 8c), PAZT fibers show DDE of $14.1 \%$, 

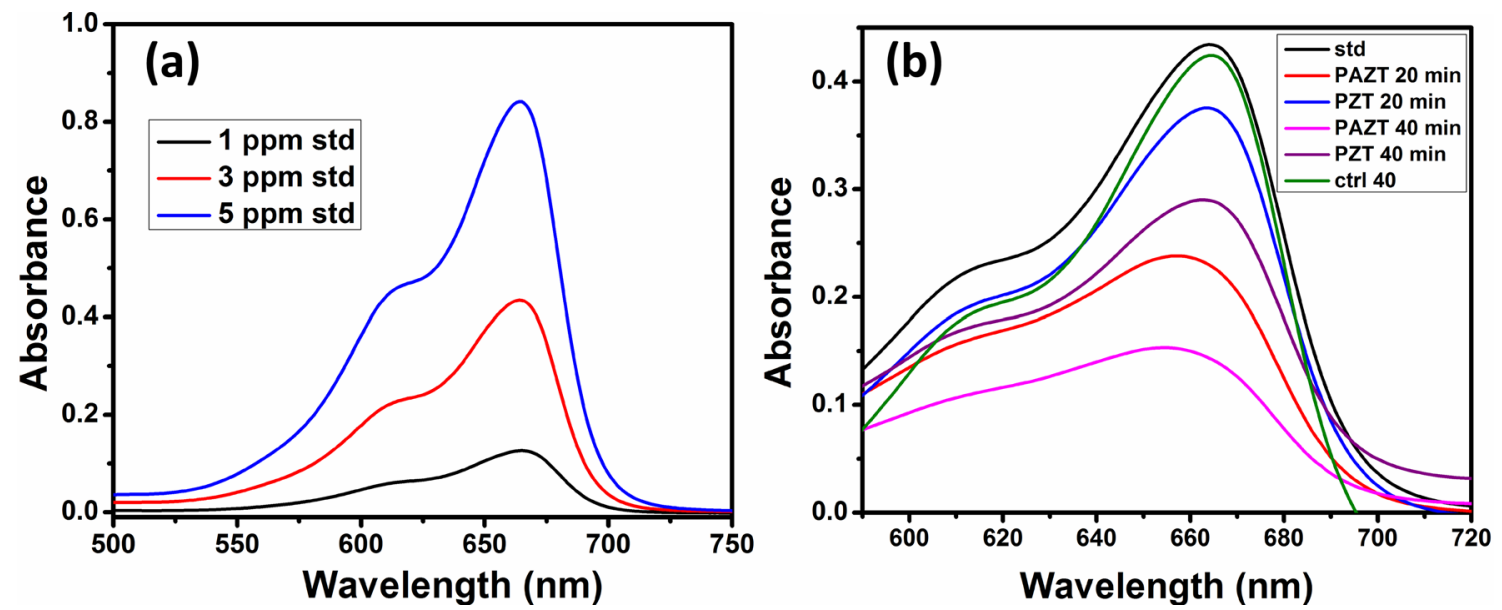

Fig. 7 a Standard curve, b UV plot for photocatalytic activity comparison of PZT and PAZT Nanofibers for MB concentration 3 ppm
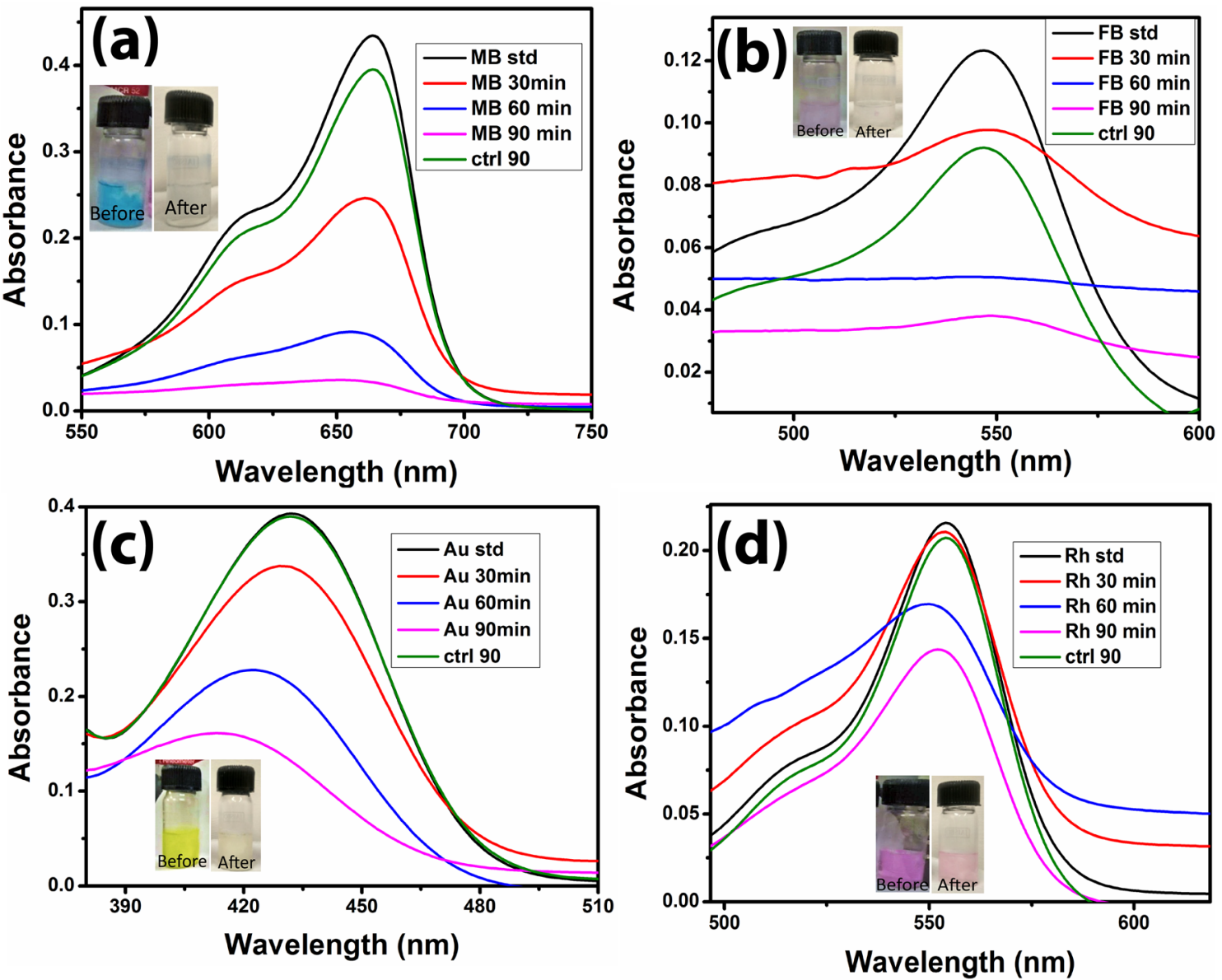

Fig. 8 UV plot of photocatalytic activity of PAZT nanofibers for a MB 3 ppm, b FB 1 ppm, c Au 5 ppm, d Rh 1 ppm (inset: water before and after removal of dye)

$44.4 \%$ and $65.0 \%$ in 30,60 and 90 min, respectively. The Au dye control sample ( $5 \mathrm{ppm})$ shows a degradation of $\sim 1 \%$ in sunlight in $90 \mathrm{~min}$.
Further, for FB (1 ppm) (Fig. 8b) and Rh (1 ppm) (Fig. 8d), DDE is $21.0 \%$ and $2.6 \%$ for $30 \mathrm{~min}, 59.9 \%$ and $23.4 \%$ for $60 \mathrm{~min}$, and $69.8 \%$ and $34.6 \%$ in $90 \mathrm{~min}$, 
respectively. This shows that the PAZT fibers are more efficient in abating $\mathrm{MB}$ dye followed by $\mathrm{FB}, \mathrm{AO}$ and $\mathrm{Rh}$. In the case of FB (1 ppm), the control (90 min) shows a degradation of almost $27 \%$ and for $\mathrm{Rh}$ (1 ppm) $3.9 \%$ under sunlight.

Table 1 shows a comparison of photocatalytic activity reported for similar kinds of materials. Although, all the reported materials have shown good performance in abating dye pollutants from water, however, in most cases the dye degradation was carried out for dyes different from our study. These studies also support our assumption of the synergic effect of $\mathrm{Ag}$ in combination with $\mathrm{ZnO}$ and $\mathrm{TiO}_{2}$ (Bian et al. 2020; Pant et al. 2013; Zhao et al. 2017). However, most of $\mathrm{Ag}$ decorated $\mathrm{TiO}_{2} / \mathrm{ZnO}$ composites are in the form of powder and have limits in easy removal of catalysts from water. As compared to related literature of PMMA/ZnO (20\% in $180 \mathrm{~min}$ ) and $\mathrm{PMMA} / \mathrm{TiO}_{2}(70 \%$ in $240 \mathrm{~min})$, the time taken by our composite fibers in abating MB dye is less, due to the synergic effect of both $\mathrm{ZnO}$ and $\mathrm{TiO}_{2}$ with similar bandgap and suppressed electron-hole recombination due to presence of Ag particles. The delay in the recombination of charge carriers is also supported by PL analysis of nanofiber materials.

Most of the times, the industrial wastewater consists of these dyes in the mixture form, so, DDE of PAZT fibers against the mixture of these four dyes was also studied. In the first experiment, the concentration of each dye was taken as same $(3 \mathrm{ppm})$ in the mixture. Figure 9 a shows the UV

Table 1 Comparison table between literature and present work for individual dyes using nanofibers

\begin{tabular}{|c|c|c|c|c|}
\hline Material & Source & Dye & Efficiency & References \\
\hline PMMA/ZnO nanofibers & UV lamp (8 W, 254 nm) & MB & $20 \%$ in $180 \mathrm{~min}$ & Zhuo et al. (2019) \\
\hline $\mathrm{PMMA} / \mathrm{TiO}_{2}$ nanofibers & UV-A & $\begin{array}{l}\text { MB } \\
\text { MO }\end{array}$ & $\begin{array}{l}70 \% \text { in } 240 \mathrm{~min} \\
50 \% \text { in } 240 \mathrm{~min}\end{array}$ & Cantarella et al. (2016) \\
\hline $\mathrm{PMMA} /$ nano- $^{-\mathrm{TiO}_{2}}$ nanofibers & Sunlight & MO & $50 \%$ in $5 \mathrm{~h}$ & Zhuo et al. (2019) \\
\hline Rutile- $\mathrm{TiO}_{2} / \mathrm{PMMA}$ nanofibers & Sun light & MO & $30 \%$ in $5 \mathrm{~h}$ & Liu et al. (2019) \\
\hline PAN/ZnO nanofibers & UV-A and B & MO & $95 \%$ in $9 \mathrm{~h}$ & Tissera et al. (2018) \\
\hline $\mathrm{PAN} / \mathrm{ZnO} / \mathrm{TiO}_{2}$ & UVC lamp $254 \mathrm{~nm}$ & MG & $99 \%$ in $204 \mathrm{~min}$ & Yar et al. (2017) \\
\hline $\mathrm{Ag} / \mathrm{TiO}_{2} / \mathrm{ZnO}$ nano-flowers & Mercury-vapor lamp & $\mathrm{RB}$ & $>80 \%$ in $200 \mathrm{~min}$ & Pant et al. (2013) \\
\hline $\mathrm{Ag} / \mathrm{ZnO} / \mathrm{AgO} / \mathrm{TiO}_{2}$ & Xenon lamp $350 \mathrm{~W}$ & $\mathrm{RhB}$ & $99.3 \%$ at $100 \mathrm{~min}$ & Bian et al. (2020) \\
\hline $\begin{array}{l}\mathrm{Ag} \text { decorated } \mathrm{TiO}_{2} / \mathrm{ZnO} \text { nano- } \\
\text { tubes }\end{array}$ & UV lamp $125 \mathrm{~W}$ & MO & $\begin{array}{l}96.7 \% \text { in } 35 \mathrm{~min} \text { for ATZ } \\
(100 \%)\end{array}$ & Zhao et al. (2017) \\
\hline PAN-ZIF-8/Ag/AgCl/ $\mathrm{TiO}_{2}$ & $600 \mathrm{~W}$ Xenon lamp $\lambda>420 \mathrm{~nm}$ & MB & $98.02 \%$ within $120 \mathrm{~min}$ & Zhan et al. (2020) \\
\hline $\mathrm{TiO}_{2} / \mathrm{ZnO}$ nanocomposite & $300 \mathrm{~W}$ halogen lamp & $\mathrm{RhB}$ & $40 \%$ in $60 \mathrm{~min}$ & K. S et al. (2017) \\
\hline $\begin{array}{l}\text { PMMA } \mathrm{Ag} / \mathrm{ZnO} / \mathrm{TiO}_{2} \text { nanofib- } \\
\text { ers }\end{array}$ & Direct sun light & $\mathrm{MB}, \mathrm{Au}, \mathrm{FB}, \mathrm{Rh}$ & $\begin{array}{l}93.4 \%, 65 \%, 69.8 \%, 34.6 \% \\
\text { In } 90 \mathrm{~min}\end{array}$ & Present work \\
\hline
\end{tabular}

$C V$ Crystal violet, $M B$ methylene blue, $R h$ or $R h B$ rhodamine blue, $M O$ methyl orange, $F B$ fuchsin basic, $M R$ methyl red, $A R 14$ acid red14, $A u$ auramine- $O, M G$ malachite green, $R B$ reactive black
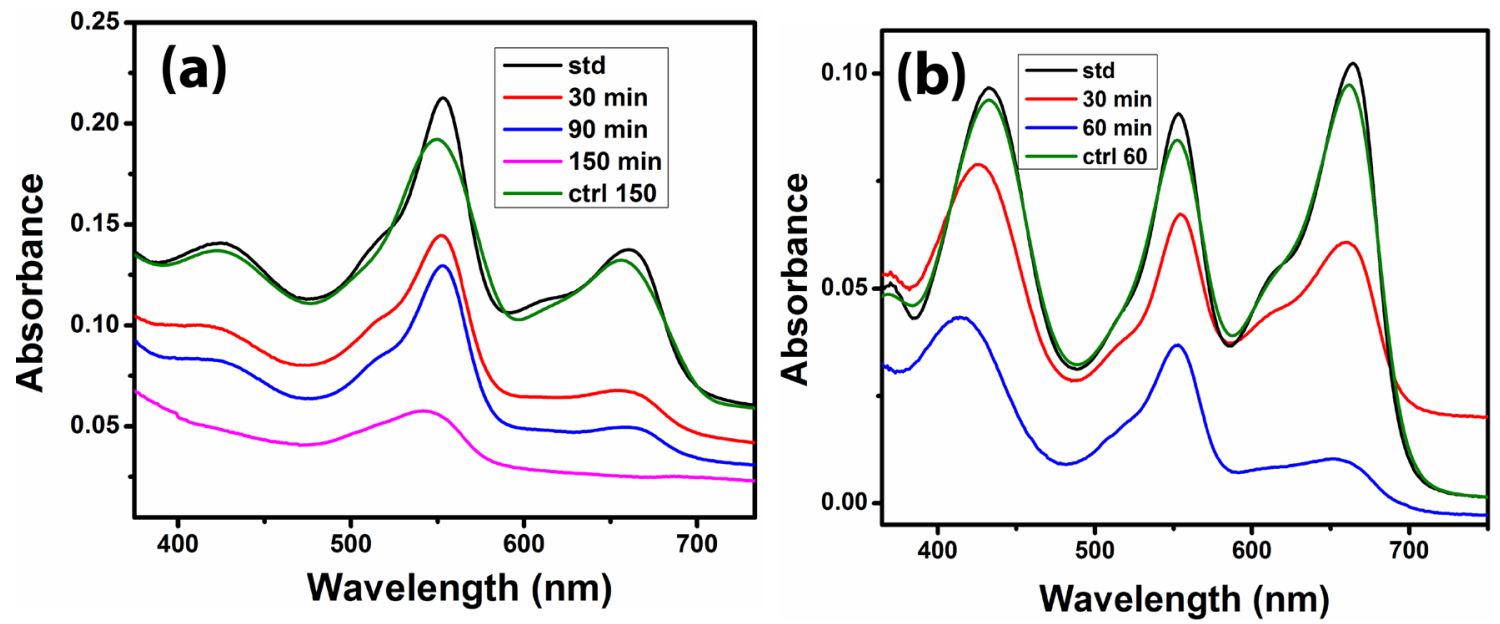

Fig. 9 UV plot of photocatalytic activity of PAZT nanofibers on mix dyes, a 3 ppm concentration for each dye, b variable concentration (FB: 1 ppm Au: 2 ppm MB: 3 ppm, Rh: 1 ppm) 
spectrophotometer analysis of the $3 \mathrm{ppm}$ dye mixture after exposure to PAZT fibers for different time intervals, i.e., 30, 90 and $150 \mathrm{~min}$. The Au and MB dyes show UV peak nearly at two different positions, i.e., 430 and $664 \mathrm{~nm}$, while FB and Rh dye show peak overlapping (peak centers at $553 \mathrm{~nm}$ ).

The DDE for peak position $430 \mathrm{~nm}(\mathrm{Au})$ is found as $30.2 \%, 41.9 \%$, and $66.0 \%$ at 30,90 and $150 \mathrm{~min}$, respectively. Also, at peak position $664 \mathrm{~nm}(\mathrm{MB})$, the dye degradation efficiency was found to be $51.5 \%, 64.0 \%$, and $81.2 \%$ at 30,90 and $150 \mathrm{~min}$, respectively. The absorption peak at $554 \mathrm{~nm}$ (pref. for Rh and FB dye) also showed dye concentration reduction with time and proved that $\mathrm{Rh}$ and FB dye have also been degraded by PAZT fibers in solar radiation along with MB and Au dyes simultaneously. The dye degradation efficiency was found to be $32.1 \%, 39.0 \%$ and $74.4 \%$ at 30,90 and $150 \mathrm{~min}$, respectively for peak position $554 \mathrm{~nm}$. The dye degradation without catalyst was found as $2.8 \%$ $(\mathrm{Au}), 10.58 \%$ (FB and $\mathrm{Rh}$ ) and $5.09 \%(\mathrm{MB})$ under daylight exposure for $150 \mathrm{~min}$.

The different concentrations of dyes mixture were also prepared containing FB (1 ppm), Au (2 ppm), MB (3 ppm), $\mathrm{Rh}(1 \mathrm{ppm})$ and tested in the presence and absence of PAZT fiber in exposure to solar radiations. Similar to the above case, three absorption peak positions were observed for the mixture, i.e., at $430(\mathrm{Au}), 554(\mathrm{FB}$ and $\mathrm{Rh})$ (Kumar and Kumar 2019; Tokalıoğlu et al. 2015) and 664 nm (MB) (Fig. 9b). The control in 60 min shows a dye degradation of $3 \%, 11.7 \%$ and $6 \%$ for $\mathrm{Au}(430 \mathrm{~nm}), \mathrm{FB}$ and $\mathrm{Rh}(554 \mathrm{~nm})$, and MB (664 nm), respectively. The dye degradation efficiency with the catalyst, at peak position $430 \mathrm{~nm}(\mathrm{Au})$ is $20.1 \%$ and $62.4 \%$ at 30 and 60 min, respectively. Also, at peak position $664 \mathrm{~nm}(\mathrm{MB})$, the dye degradation efficiency is $41.4 \%$ and $90.9 \%$ at 30 and $60 \mathrm{~min}$, respectively. The absorption peak at $554 \mathrm{~nm}$ (for $\mathrm{Rh}$ and FB dye) also shows reduction with time and proved that $\mathrm{Rh}$ and $\mathrm{FB}$ dye have also been degraded by PAZT fibers in solar radiation along with $\mathrm{MB}$ and Au dyes simultaneously. The dye degradation efficiency is found to be $26.0 \%$ and $90.3 \%$ at 30 and $60 \mathrm{~min}$, respectively, for peak position $554 \mathrm{~nm}$. It is observed that the standard solution absorption differs for the same concentration in case of single dye and mix dyes that may be due to some dye-dye interaction and color change on mixing different color dyes. These results signify the importance of synthesized PAZT fibers that these can be used in water purification by degrading individual as well as a combination of different dyes, i.e., $\mathrm{MB}, \mathrm{FB}, \mathrm{Au}$ and $\mathrm{Rh}$.

Only a few reports (Adamek et al. 2013; Akerdi et al. 2020; Chomkitichai et al. 2019; Gupta et al. 2015b; Xie et al. 2018) are available in the literature on mixed dye removal and most of these reports demonstrate the removal of two dyes that is different from the dyes studied in this work. As can be seen from Table 2, researchers have tried $\mathrm{SrTiO}_{3}$ (Xie et al. 2018), multi-phase $\mathrm{BiVO}_{4}$ (Chomkitichai et al. 2019), graphene nanosheets (Gunture et al. 2019), and $\mathrm{CoFe}_{2} \mathrm{O}_{4}-\mathrm{RGO}$ (Moitra et al. 2016) photocatalyst for removal of a binary mixture of $\mathrm{MB}$ and $\mathrm{RhB}$ and/or in

Table 2 Comparison table between literature and present work for dye mixture

\begin{tabular}{|c|c|c|c|c|}
\hline Materials & Ex. source & Dye mixture & Dye removal capacity & Refs. \\
\hline $\begin{array}{l}\mathrm{SrTiO}_{3} \text { synthesized using } \\
\text { sodium carboxymethylcel- } \\
\text { lulose }\end{array}$ & $\begin{array}{l}\text { Mercury lamp } \\
365 \mathrm{~nm}\end{array}$ & RhB-MB binary solution & $\sim 100 \%$ in $180 \mathrm{~min}$ & Xie et al. (2018) \\
\hline $\mathrm{Ag}^{+}$doped $\mathrm{TiO}_{2}$ & UV lamp (365 nm) & $\begin{array}{l}\text { Crystal Violet and Methyl } \\
\text { Red }\end{array}$ & $\begin{array}{l}>99 \% \text { on UV irradiation for } \\
90 \mathrm{~min}\end{array}$ & Gupta et al. (2006) \\
\hline $\mathrm{TiO}_{2}$ & UV-a lamps & $\begin{array}{l}\text { Azodyes effluent from } \\
\text { industry }\end{array}$ & $\begin{array}{r}28 \%(340 \mathrm{~nm}), 40(430 \mathrm{~nm}) \\
58(540 \mathrm{~nm}), 84(610 \mathrm{~nm})\end{array}$ & Adamek et al. (2013) \\
\hline Multi-phase $\mathrm{BiVO}_{4}$ & UV lamp (254 nm) & $\mathrm{MB}$ and $\mathrm{RhB}$ & $\begin{array}{l}74 \% \text { and } 21 \% \text { for catalyst } \\
(0.8 \mathrm{~g} / \mathrm{L}) 60 \mathrm{~min}\end{array}$ & Chomkitichai et al. (2019) \\
\hline $\mathrm{GO}^{-\mathrm{TiO}_{2}}$-graphite electrode & 9 W UV lamp & MB and AR14 & $\begin{array}{l}86.74 \%(\mathrm{MB}) \text { and } \\
82.48 \%(\mathrm{AR} 14) \text { in } 67 \mathrm{~min} \text { at } \\
\text { pH } 10\end{array}$ & Akerdi et al. (2020) \\
\hline Graphene nanosheets & Sun light & $\mathrm{CV}, \mathrm{RhB}$ and $\mathrm{MB}$ & $\begin{array}{l}\sim 99.9 \% \text { in } 180 \min (\mathrm{MB}) \\
225 \min (\mathrm{RhB} \text { and } \mathrm{CV})\end{array}$ & Gunture et al. (2019) \\
\hline $\mathrm{CoFe}_{2} \mathrm{O}_{4}-\mathrm{RGO}(25 \%)$ catalyst & $100 \mathrm{~W}$ reading lamp & $\begin{array}{l}\text { Methyl orange, Methylene } \\
\text { blue, Rhodamine B }\end{array}$ & $99.9 \%$ removal in $120 \mathrm{~min}$ & Moitra et al. (2016) \\
\hline \multirow[t]{2}{*}{$\begin{array}{l}\mathrm{PMMA} \mathrm{Ag} / \mathrm{ZnO} / \mathrm{TiO}_{2} \\
\text { nanofibers }\end{array}$} & \multirow[t]{2}{*}{ Sun light } & $\begin{array}{l}\mathrm{MB}, \mathrm{Au}, \mathrm{FB}, \mathrm{Rh} \\
\text { Each } 3 \mathrm{ppm}\end{array}$ & $\begin{array}{l}81.2 \% 66.0 \% \\
74.4 \% \text { in } 150 \mathrm{~min}\end{array}$ & Present work \\
\hline & & $\begin{array}{l}\text { MB (3 ppm), Au (5 ppm), FB } \\
\text { (1 ppm), Rh (1 ppm) }\end{array}$ & $\begin{array}{l}90.9 \% 62.4 \% \\
90.3 \% \text { in } 60 \mathrm{~min}\end{array}$ & Present work \\
\hline
\end{tabular}

$C V$ crystal violet, $M B$ methylene blue, $R h$ or $R h B$ rhodamine blue, $M O$ methyl orange, $F B$ fuchsin basic, $M R$ methyl red, $A R 14$ acid red14, $A u$ auramine- $O$ 
combination with other dyes. Also, the materials used are in the form of nanomaterials powder as the catalyst. The powder form of the catalyst has the disadvantage of postdegradation removal and also some amount of these may remain in some amount in water, which generates secondary contamination that is harmful to the human body. In our case, $\mathrm{Ag} / \mathrm{ZnO} / \mathrm{TiO}_{2}$ nanomaterials are wrapped in the polymer nanofiber matrix, thus making it suitable for realtime application.

The PAZT nanofibers show good photocatalytic activity which may be due to the uniform dispersion of $\mathrm{Ag}, \mathrm{ZnO}$ and $\mathrm{TiO}_{2}$ materials in nanofibers, resulting in electron-hole separation to high extent that is enough to perform photocatalytic action for a long time. Also, it is reported that sunlight-induced photocatalysis exhibits higher efficiency and can offer a feasible approach in real-time application (Gunture et al. 2019).

\section{Antibacterial activity}

The second goal of the present work is to evaluate the antibacterial performance of synthesized fiber membranes. Antibacterial activity of PAZT and PZT composite fibers membrane was studied by the test of the zone of inhibition using Gram-negative bacterium E. coli strain $D \# 5 \alpha$. Nanofiber membranes were cut into small pieces and placed under UV exposure for $10 \mathrm{~min}$. Then nanofibers were placed on the surface of the Petri plate and solidified agar medium containing bacterial spread was poured. The plates were lid closed, sealed and kept in an incubator for $24 \mathrm{~h}$ at $37^{\circ} \mathrm{C}$. One control sample (without nanofibers sheet) was also kept in an incubator at the same conditions. Figure 10 shows the images of the plates after $24 \mathrm{~h}$ incubation. Figure 10(a) shows the image of the control sample. It can be seen that $E$. coli strain $\mathrm{D} \# 5 \alpha$ bacteria have grown uniformly in all directions over the agar medium. In the case of PZT nanofibers loaded sample, inhibition zones can be seen clearly around the nanofibers (blue circles). The inhibition efficiency for PZT (Fig. 10b) nanofibers sheet was found to be good, but lower in comparison to PAZT (Fig. 10c) nanofibers. The area of the zone of inhibition(\%) was calculated using Image $\mathbf{J}$ software for each fiber sample shown in Fig. 10. The results have been summarized in Table 2.

As can be seen in Table 3, PZT nanofibers show an inhibition zone area of $\sim 172 \%$ w.r.t. nanofiber sample which increases to $213 \%$ for PAZT nanofibers due to the synergic antibacterial effect of $\mathrm{Ag}$ with $\mathrm{ZnO}$ and $\mathrm{TiO}_{2} . \mathrm{Ag}$ metal particles in contact with $\mathrm{ZnO}$ and $\mathrm{TiO}_{2}$ reduces the bandgap energy by increasing the $\mathrm{e}^{-}-\mathrm{h}^{+}$charge separation time and thus increases the antibacterial activity as compared to nanofibers containing only $\mathrm{ZnO}$ and $\mathrm{TiO}_{2}$ (Nigussie et al. 2018). The detailed antibacterial mechanism is shown in Fig. 11

Also, it is reported (Yamanaka et al. 2005) that noble metal ions inhibit the enzymes for ATP hydrolysis and expression of ribosomal proteins by hindering DNA replication of bacteria (Fig. 11). The synergic effect of silver nanoparticles with $\mathrm{ZnO}$ and $\mathrm{TiO}_{2}$ is due to its plasmon resonance, where the electrons present on the surface of $\mathrm{Ag}$ particles move to the conduction band of $\mathrm{ZnO}$ and $\mathrm{TiO}_{2}$ and get trapped by $\mathrm{O}_{2}$ molecules to generate $\mathrm{O}_{2}$, dOOH,

Table 3 Zone of inhibition against E. coli bacteria for PZT and PAZT nanofibers

\begin{tabular}{llllll}
\hline Total area of inhibition $(\%)$ & & & & \\
\hline Sample name & 1 & 2 & 3 & 4 & Average \\
\hline PZT nanofibers & 168.0 & 175.8 & 171.4 & 174.2 & 172.4 \\
PAZT nanofibers & 184.4 & 239.8 & 214.7 & 211.5 & 212.6 \\
\hline
\end{tabular}
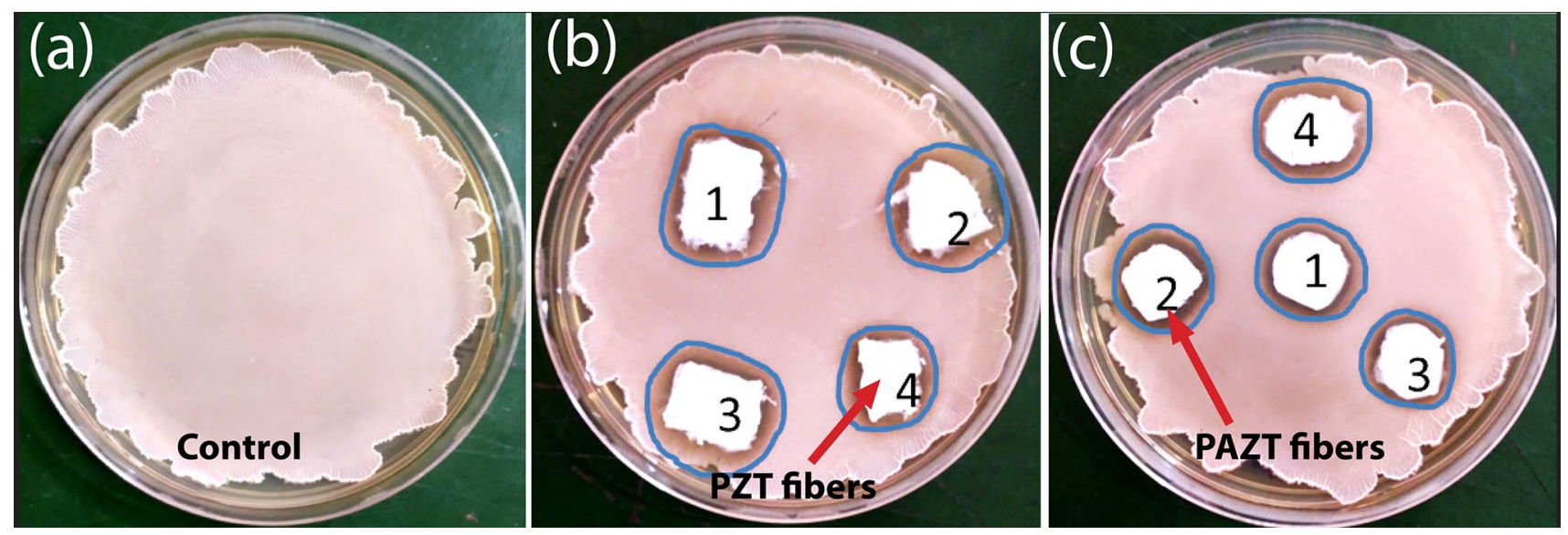

Fig. 10 Antibacterial zone inhibition test for a control sample, b PZT and $\mathbf{c}$ PAZT nanofibers

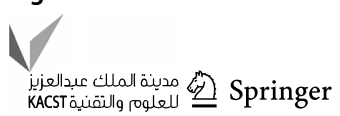


Fig. 11 The proposed mechanism for antibacterial action of PZT and PAZT nanofibers

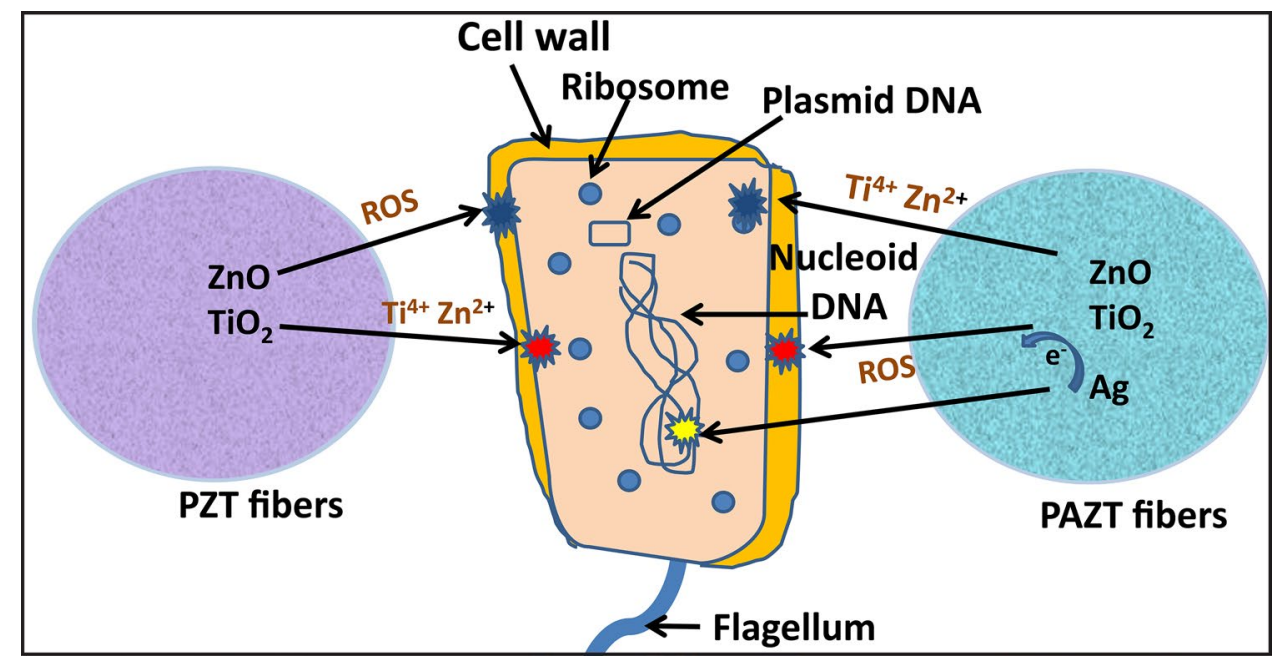

and $\mathrm{dOH}$ (ROS) for complete bacterial destruction(Pant et al. 2013).

\section{Conclusions}

Synthesis of tricomponent PMMA composite fiber membrane containing $\mathrm{ZnO}, \mathrm{TiO}_{2}$ and $\mathrm{Ag}$ particles was carried out successfully using the electrospinning technique. In the case of PAZT fibers, the diameter decreases due to the addition of $\mathrm{Ag}$ conducting particles as a consequence of more elongation at the same processing conditions. The particles are encapsulated inside the fiber and deposited on the surface of fibers. The nanofibers are proven to be effective in abating MB (93.4\%), $\mathrm{Rh}(34.6 \%), \mathrm{Au}(65.0 \%)$ and $\mathrm{FB}(69.8 \%)$ dyes individually in $90 \mathrm{~min}$. These nanofibers have demonstrated their utility in abating the mixture of these dyes for $3 \mathrm{ppm}$ concentration of each as well as in different concentrations successfully. The addition of silver in the $\mathrm{ZnO} / \mathrm{TiO}_{2}$ composite further enhances its photocatalytic activity due to the SPR effect of Ag metal ions, lowering the recombination rate. The zone of inhibition against Gram-negative bacteria E. Coli is measured as 172\% for PZT fibers, which enhances to $215 \%$ for PAZT fibers due to the synergic bactericidal effect of $\mathrm{Ag}$ with $\mathrm{ZnO}$ and $\mathrm{TiO}_{2}$.

Acknowledgements The authors would like to thank Dr. D. K. Aswal, Director, CSIR-NPL for his kind permission for publication. One of the authors, Dr. Ashish Gupta, thanks the Council of Scientific and Industrial Research (CSIR) for research associateship award (31/01(0499)/2018-EMR-I) to carry out this research work. The authors also like to thank Dr. Jai Tawale and Mr. Dinesh Singh, for SEM and TEM characterization of composite nanofibers.

\section{Compliance with ethical standards}

Conflict of interest The authors declare no conflict of interest.

\section{References}

Aboua KN, Yobouet YA, Yao KB, Goné DL, Trokourey A (2015) Investigation of dye adsorption onto activated carbon from the shells of Macoré fruit. J Environ Manage 156:10-14

Adamek E, Baran W, Ziemiańska J, Sobczak A (2013) The comparison of photocatalytic degradation and decolorization processes of dyeing effluents. Int J Photoenergy 2013:578191

Akerdi AG, Bahrami SH, Pajootan E (2020) Modeling and optimization of Photocatalytic Decolorization of binary dye solution using graphite electrode modified with Graphene oxide and $\mathrm{TiO}_{2}$. J Environ Health Sci Eng 18(1):51-62

Arslan I, Balcioğlu IA (1999) Degradation of commercial reactive dyestuffs by heterogenous and homogenous advanced oxidation processes: a comparative study. Dyes Pigm 43(2):95-108

Augugliaro V, Baiocchi C, Prevot AB, García-López E, Loddo V, Malato S, Marcí G, Palmisano L, Pazzi M, Pramauro E (2002) Azo-dyes photocatalytic degradation in aqueous suspension of $\mathrm{TiO}_{2}$ under solar irradiation. Chemosphere 49(10): 1223-1230

Bian H, Zhang Z, Xu X, Gao Y, Wang T (2020) Photocatalytic activity of $\mathrm{Ag} / \mathrm{ZnO} / \mathrm{AgO} / \mathrm{TiO}_{2}$ composite. Physica E 124:114236

Bouazizi A, Breida M, Achiou B, Ouammou M, Calvo JI, Aaddane A, Younssi SA (2017) Removal of dyes by a new nano-TiO2 ultrafiltration membrane deposited on low-cost support prepared from natural Moroccan bentonite. Appl Clay Sci 149:127-135

Butler EB, Hung Y-T, Mulamba O (2017) The effects of chemical coagulants on the decolorization of dyes by electrocoagulation using response surface methodology (RSM). Appl Water Sci 7(5):2357-2371

Cantarella M, Sanz R, Buccheri MA, Ruffino F, Rappazzo G, Scalese S, Impellizzeri G, Romano L, Privitera V (2016) Immobilization of nanomaterials in PMMA composites for photocatalytic removal of dyes, phenols and bacteria from water. J Photochem Photobiol A 321:1-11

Chaudhary A, Gupta A, Mathur RB, Dhakate SR (2014) Effective antimicrobial filter from electrospun polyacrylonitrile-silver composite nanofibers membrane for conducive environment. Adv Mater Lett 5(10):562-568

Chavan RB (2001) Indian textile industry-environmental issues. Indian J Fibre Text Res 26(1-2):11-21

Chomkitichai W, Pama J, Jaiyen P, Pano S, Ketwaraporn J, Pookmanee P, Phanichphant S, Jansanthea P (2019) Dye Mixtures 
degradation by multi-phase $\mathrm{BiVO}_{4}$ PhotOcatalyst. Appl Mech Mater 886:138-145

Cooper P (1993) Removing colour from dyehouse waste watersa critical review of technology available. J Soc Dyers Colour 109(3):97-100

Correia VM, Stephenson T, Judd SJ (1994) Characterisation of textile wastewaters-a review. Environ Technol 15(10):917-929

Di Mauro A, Cantarella M, Nicotra G, Pellegrino G, Gulino A, Brundo MV, Privitera V, Impellizzeri G (2017) Novel synthesis of $\mathrm{ZnO} / \mathrm{PMMA}$ nanocomposites for photocatalytic applications. Sci Rep 7:40895

Divya KS, Xavier MM, Vandana PV, Reethu VN, Mathew S (2017) A quaternary $\mathrm{TiO} 2 / \mathrm{ZnO} / \mathrm{RGO} / \mathrm{Ag}$ nanocomposite with enhanced visible light photocatalytic performance. New J Chem 41(14):6445-6454

Fageria P, Gangopadhyay S, Pande S (2014) Synthesis of ZnO/Au and $\mathrm{ZnO} / \mathrm{Ag}$ nanoparticles and their photocatalytic application using UV and visible light. RSC Adv 4(48):24962-24972

Galindo C, Jacques P, Kalt A (2001) Photooxidation of the phenylazonaphthol AO20 on $\mathrm{TiO}_{2}$ : kinetic and mechanistic investigations. Chemosphere 45(6-7):997-1005

Guo K, Gao B, Li R, Wang W, Yue Q, Wang Y (2018) Flocculation performance of lignin-based flocculant during reactive blue dye removal: comparison with commercial flocculants. Environ Sci Pollut Res 25(3):2083-2095

Gupta AK, Pal A, Sahoo C (2006) Photocatalytic degradation of a mixture of Crystal Violet (Basic Violet 3) and Methyl Red dye in aqueous suspensions using $\mathrm{Ag}+$ doped TiO2. Dyes Pigm 69(3):224-232

Gupta A, Nandanwar DV, Dhakate SR (2015a) Electrospun selfassembled $\mathrm{ZnO}$ nanofibers structures for photocatalytic activity in natural solar radiations to degrade acid fuchsin dye. Adv Mater Lett 6(8):706-710

Gupta V, Khamparia S, Tyagi I, Jaspal D, Malviya A (2015b) Decolorization of mixture of dyes: a critical review.

Gupta A, Gurunathan P, Ramesha K, Singh M, Dhakate SR (2019) Effect of heat treatment temperature on energy storage performance of PAN co-MMA based carbon nanofibers as freestanding lithium ion batteries anode. Energy Storage 1(6):e89

Hidalgo AM, Gómez M, Murcia MD, Serrano M, RodríguezSchmidt R, Escudero PA (2018) Behaviour of polysulfone ultrafiltration membrane for dyes removal. Water Sci Technol 77(7-8):2093-2100

Hussain W, Malik H, Hussain RA, Hussain H, Green IR, Marwat S, Bahadur A, Iqbal S, Farooq MU, Li H, Badshah A (2019) Synthesis of MnS from single- and multi-source precursors for photocatalytic and battery applications. J Electron Mater 48(4):2278-2288

Hussain W, Malik H, Khan MA, Iqbal MJ, Hussain RA, Shoukat R, Khan Y, Badshah A, Sulaman M, Li H (2019) Comparative study of cobalt sulphides properties for photocatalytic and battery applications. Semicond Sci Technol 34(9):095015

Im JS, Kim MI, Lee Y-S (2008) Preparation of PAN-based electrospun nanofiber webs containing $\mathrm{TiO}_{2}$ for photocatalytic degradation. Mater Lett 62(21-22):3652-3655

Kumar TKM, P., Kumar S.K., A. (2019) Visible-light-induced degradation of rhodamine B by nanosized Ag2S-ZnS loaded on cellulose. Photochem Photobiol Sci 18(1):148-154

Kumar P, Gupta A, Dhakate SR, Mathur RB, Nagar S, Gupta VK (2013) Covalent immobilization of xylanase produced from B acillus pumilus SV-85 S on electrospun polymethyl methacrylate nanofiber membrane. Biotechnol Appl Biochem 60(2):162-169

Kumar S, Jain G, Kumar K, Gupta A, Singh BP, Dhakate SR (2020) A facile fabrication of poly(methyl methacrylate) $/ \alpha-\mathrm{NaYF}_{4}: \mathrm{Eu}^{3+}$ tunable electrospun photoluminescent nanofibers. Appl Nanosci. https://doi.org/10.1007/s1320 4-020-01499-4

Liu J, Zhuo Y, Wang Y, Li Q, Ren X (2019) Preparation and characterization of R-TiO2/PMMA nanofibers by electrospinning. Ferroelectrics 548(1):8-14

Ma W, Lu Z, Zhang M (1998) Investigation of structural transformations in nanophase titanium dioxide by Raman spectroscopy. Appl Phys A 66(6):621-627

Malwal D, Gopinath P (2017) Efficient adsorption and antibacterial properties of electrospun $\mathrm{CuO}-\mathrm{ZnO}$ composite nanofibers for water remediation. J Hazard Mater 321:611-621

Michaels AM, Nirmal M, Brus LE (1999) Surface enhanced Raman spectroscopy of individual rhodamine 6G Molecules On Large Ag nanocrystals. J Am Chem Soc 121(43):9932-9939

Moheman A, Alam MS, Gupta A, Dhakate S, Kumar A, Mohammad A (2016) Fabrication of nanofiber stationary phases from chopped polyacrylonitrile co-polymer microfibers for use in ultrathin layer chromatography of amino acids. RSC Adv 6(93):90100-90110

Moitra D, Chandel M, Ghosh BK, Jani RK, Patra MK, Vadera SR, Ghosh NN (2016) A simple 'in situ' co-precipitation method for the preparation of multifunctional $\mathrm{CoFe}_{2} \mathrm{O}_{4}$-reduced graphene oxide nanocomposites: excellent microwave absorber and highly efficient magnetically separable recyclable photocatalyst for dye degradation. RSC Adv 6(80):76759-76772

Mokif LA (2019) Removal methods of synthetic dyes from industrial wastewater: a review. Mesopot Environ J 5(1):23-40

Molinari R, Mungari M, Drioli E, Di Paola A, Loddo V, Palmisano L, Schiavello M (2000) Study on a photocatalytic membrane reactor for water purification. Catal Today 55(1-2):71-78

Molinari R, Grande C, Drioli E, Palmisano L, Schiavello M (2001) Photocatalytic membrane reactors for degradation of organic pollutants in water. Catal Today 67(1-3):273-279

Molinari R, Borgese M, Drioli E, Palmisano L, Schiavello M (2002) Hybrid processes coupling photocatalysis and membranes for degradation of organic pollutants in water. Catal Today 75(1-4):77-85

Molinari R, Palmisano L, Drioli E, Schiavello M (2002) Studies on various reactor configurations for coupling photocatalysis and membrane processes in water purification. J Membr Sci 206(1-2):399-415

Moore AT, Vira A, Fogel S (1989) Biodegradation of trans-1,2-dichloroethylene by methane-utilizing bacteria in an aquifer simulator. Environ Sci Technol 23(4):403-406

Nigussie GY, Tesfamariam GM, Tegegne BM, Weldemichel YA, Gebreab TW, Gebrehiwot DG, Gebremichel GE (2018) Antibacterial activity of $\mathrm{Ag}$-doped $\mathrm{TiO}_{2}$ and $\mathrm{Ag}$-doped $\mathrm{ZnO}$ nanoparticles. Int J Photoenergy. https://doi.org/10.1155/2018/5927485

Pant HR, Pant B, Sharma RK, Amarjargal A, Kim HJ, Park CH, Tijing LD, Kim CS (2013) Antibacterial and photocatalytic properties of $\mathrm{Ag} / \mathrm{TiO} 2 / \mathrm{ZnO}$ nano-flowers prepared by facile one-pot hydrothermal process. Ceram Int 39(2):1503-1510

Pastoriza-Santos I, Liz-Marzán LM (2009) N,N-dimethylformamide as a reaction medium for metal nanoparticle synthesis. Adv Func Mater 19(5):679-688

Patil SS, Shinde VM (1988) Biodegradation studies of aniline and nitrobenzene in aniline plant wastewater by gas chromatography. Environ Sci Technol 22(10):1160-1165

Pei CC, Leung WW-F (2013) Enhanced photocatalytic activity of electrospun $\mathrm{TiO}_{2} / \mathrm{ZnO}$ nanofibers with optimal anatase/rutile ratio. Catal Commun 37:100-104

Phan D-N, Kim I-S (2020) Composite nanofibers: recent progress in adsorptive removal and photocatalytic degradation of dyes fiber composites. IntechOpen, London 
Phan D-N, Dorjjugder N, Saito Y, Taguchi G, Ullah A, Kharaghani D, Kim I-S (2020) The synthesis of silver-nanoparticle-anchored electrospun polyacrylonitrile nanofibers and a comparison with as-spun silver/polyacrylonitrile nanocomposite membranes upon antibacterial activity. Polym Bull 77(8):4197-4212

Piaskowski K, Świderska-Dąbrowska R, Zarzycki PK (2018) Dye removal from water and wastewater using various physical, chemical, and biological processes. J AOAC Int 101(5):1371-1384

Pirkanniemi K, Sillanpää M (2002) Heterogeneous water phase catalysis as an environmental application: a review. Chemosphere 48(10): 1047-1060

Sahinkaya E, Sahin A, Yurtsever A, Kitis M (2018) Concentrate minimization and water recovery enhancement using pellet precipitator in a reverse osmosis process treating textile wastewater. J Environ Manage 222:420-427

Sakthivel S, Neppolian B, Shankar M, Arabindoo B, Palanichamy M, Murugesan V (2003) Solar photocatalytic degradation of azo dye: comparison of photocatalytic efficiency of $\mathrm{ZnO}$ and $\mathrm{TiO}_{2}$. Sol Energy Mater Sol Cells 77(1):65-82

Šćepanović M, Grujić-Brojčin M, Vojisavljević K, Bernik S, Srećković $\mathrm{T}$ (2010) Raman study of structural disorder in $\mathrm{ZnO}$ nanopowders. J Raman Spectrosc 41(9):914-921

Sehar S, Naz I, Perveen I, Ahmed S (2019) Superior dye degradation using $\mathrm{SnO}_{2}-\mathrm{ZnO}$ hybrid heterostructure catalysts. Korean J Chem Eng 36(1):56-62

Shahi K, Singh R, Singh J, Aleksandrova M, Singh AK (2020) Synthesis of Ag nanoparticle-decorated $\mathrm{ZnO}$ nanorods adopting the low-temperature hydrothermal method. J Electron Mater 49(1):637-642

Shamraiz U, Hussain RA, Badshah A, Raza B, Saba S (2016) Functional metal sulfides and selenides for the removal of hazardous dyes from Water. J Photochem Photobiol B 159:33-41

Sharma R, Singh N, Gupta A, Tiwari S, Tiwari SK, Dhakate SR (2014) Electrospun chitosan-polyvinyl alcohol composite nanofibers loaded with cerium for efficient removal of arsenic from contaminated water. J Mater Chem A 2(39):16669-16677

Singh AG, Bhati A, Khare P, Tripathi KM, Sonkar SK (2019) Soluble graphene nanosheets for the sunlight-induced photodegradation of the mixture of dyes and its environmental assessment. Sci Rep 9(1):2522

Sopajaree K, Qasim S, Basak S, Rajeshwar K (1999a) An integrated flow reactor-membrane filtration system for heterogeneous photocatalysis. Part I: experiments and modelling of a batch-recirculated photoreactor. J Appl Electrochem 29(5):533-539

Sopajaree K, Qasim S, Basak S, Rajeshwar K (1999b) An integrated flow reactor-membrane filtration system for heterogeneous photocatalysis. Part II: experiments on the ultrafiltration unit and combined operation. J Appl Electrochem 29(9):1111-1118

Stylidi M, Kondarides DI, Verykios XE (2003) Pathways of solar lightinduced photocatalytic degradation of azo dyes in aqueous $\mathrm{TiO} 2$ suspensions. Appl Catal B 40(4):271-286

Thavasi V, Singh G, Ramakrishna S (2008) Electrospun nanofibers in energy and environmental applications. Energy Environ Sci 1(2):205-221

Tissera ND, Wijesena RN, Sandaruwan CS, de Silva RM, de Alwis A, de Silva KMN (2018) Photocatalytic activity of ZnO nanoparticle encapsulated poly(acrylonitrile) nanofibers. Mater Chem Phys 204:195-206
Tokalığlu Ş, Yavuz E, Aslantaş A, Şahan H, Taşkın F, Patat Ş (2015) Spectrophotometric determination of basic fuchsin from various water samples after vortex assisted solid phase extraction using reduced graphene oxide as an adsorbent. Spectrochim Acta Part A Mol Biomol Spectrosc 149:378-384

Vanaja A, Ramaraju G, Srinivasa Rao K (2016) Role of NaOH concentration on structural, morphological and optical properties of $\mathrm{ZnO}$ nanopowders synthesized by solgel process. Int J Techno Chem Res 2(2):110-120

Xia M, Su Z, Zhang S (2012) Raman spectra of bilayer graphene covered with Poly (methyl methacrylate) thin film. AIP Adv 2(3):032122

Xie J, He Y, Wang H, Duan M, Tang J, Wang Y, Chamas M, Wang H (2018) Photocatalytic degradation of binary dyes mixture over $\mathrm{SrTiO}_{3}$ synthesized using sodium carboxymethylcellulose additive. Russ J Phys Chem A 92(4):809-815

Yamanaka M, Hara K, Kudo J (2005) Bactericidal Actions of a silver ion solution on Escherichia coli studied by energy-filtering transmission electron microscopy and proteomic analysis. Appl Environ Microbiol 71(11):7589

Yar A, Haspulat B, Üstün T, Eskizeybek V, Avcı A, Kamış H, Achour S (2017) Electrospun $\mathrm{TiO}_{2} / \mathrm{ZnO} / \mathrm{PAN}$ hybrid nanofiber membranes with efficient photocatalytic activity. RSC Adv 7(47):29806-29814

Younis A, Chu D, Kaneti YV, Li S (2016) Tuning the surface oxygen concentration of 111 surrounded ceria nanocrystals for enhanced photocatalytic activities. Nanoscale 8(1):378-387

Younis A, Shirsath SE, Shabbir B, Li S (2018) Controllable dynamics of oxygen vacancies through extrinsic doping for superior catalytic activities. Nanoscale 10(39):18576-18585

Zamiri R, Rebelo A, Zamiri G, Adnani A, Kuashal A, Belsley MS, Ferreira J (2014) Far-infrared optical constants of $\mathrm{ZnO}$ and $\mathrm{ZnO} /$ Ag nanostructures. RSC Adv 4(40):20902-20908

Zhan Y, Lan J, Shang J, Yang L, Guan X, Li W, Chen S, Qi Y, Lin S (2020) Durable ZIF-8/Ag/AgCl/TiO2 decorated PAN nanofibers with high visible light photocatalytic and antibacterial activities for degradation of dyes. J Alloy Compd 822:153579

Zhang M (1996) Decolorization and biodegradability of dyeing wastewater treated by a $\mathrm{TiO}_{2}$-sensitized photo-oxidation process. Water Sci Technol 34(9):49-55

Zhang W, He Y, Zhang M, Yin Z, Chen Q (2000) Raman scattering study on anatase $\mathrm{TiO}_{2}$ nanocrystals. J Phys D Appl Phys 33(8):912

Zhao S, Cheng Z, Kang L, Li M, Gao Z (2017) The facile preparation of $\mathrm{Ag}$ decorated $\mathrm{TiO} 2 / \mathrm{ZnO}$ nanotubes and their potent photocatalytic degradation efficiency. RSC Adv 7(79):50064-50071

Zheng Y, Zheng L, Zhan Y, Lin X, Zheng Q, Wei K (2007) Ag/ZnO heterostructure nanocrystals: synthesis, characterization, and photocatalysis. Inorg Chem 46(17):6980-6986

Zhuo Y, Liu J, Wang Y, Li Q, Xu X, Ren X (2019) Preparation and photocatalytic property of electrospun nano$\mathrm{TiO} 2 /$ poly(methylmethacrylate) nanofibres. Ferroelectrics 548(1):143-149

Publisher's Note Springer Nature remains neutral with regard to jurisdictional claims in published maps and institutional affiliations 